\title{
Immunotherapy advances for mesothelioma treatment
}

DOI:

10.1080/14737140.2017.1358091

\section{Document Version}

Accepted author manuscript

Link to publication record in Manchester Research Explorer

\section{Citation for published version (APA):}

Bakker, E. Y., Guazzelli, A., Ashtiani, F., Demonacos, C., Krstic-Demonacos, M., \& Mutti, L. (2017).

Immunotherapy advances for mesothelioma treatment. Expert Review of Anticancer Therapy, [IERY 1358091]. https://doi.org/10.1080/14737140.2017.1358091

\section{Published in:}

Expert Review of Anticancer Therapy

\section{Citing this paper}

Please note that where the full-text provided on Manchester Research Explorer is the Author Accepted Manuscript or Proof version this may differ from the final Published version. If citing, it is advised that you check and use the publisher's definitive version.

\section{General rights}

Copyright and moral rights for the publications made accessible in the Research Explorer are retained by the authors and/or other copyright owners and it is a condition of accessing publications that users recognise and abide by the legal requirements associated with these rights.

\section{Takedown policy}

If you believe that this document breaches copyright please refer to the University of Manchester's Takedown Procedures [http://man.ac.uk/04Y6Bo] or contact uml.scholarlycommunications@manchester.ac.uk providing relevant details, so we can investigate your claim.

\section{OPEN ACCESS}




\section{Immunotherapy advances for mesothelioma treatment}

\section{Emyr Bakker, Alice Guazzelli, Firozeh Ashtiani, Constantinos Demonacos, Marija Krstic-Demonacos \& Luciano Mutti}

To cite this article: Emyr Bakker, Alice Guazzelli, Firozeh Ashtiani, Constantinos Demonacos, Marija Krstic-Demonacos \& Luciano Mutti (2017): Immunotherapy advances for mesothelioma treatment, Expert Review of Anticancer Therapy, DOI: 10.1080/14737140.2017.1358091

To link to this article: http://dx.doi.org/10.1080/14737140.2017.1358091

Accepted author version posted online: 20 Jul 2017.

Submit your article to this journal $₫$

Џll Article views: 3

Q View related articles $₫$

View Crossmark data $\asymp$ 
Review

\section{Immunotherapy advances for mesothelioma treatment}

Emyr Bakker ${ }^{1}$, Alice Guazzelli ${ }^{1}$, Firozeh Ashtiani ${ }^{1}$, Constantinos Demonacos ${ }^{2}$, Marija Krstic$\operatorname{Demonacos}^{1}$, and Luciano Mutti*1

${ }^{1}$ Biomedical Research Centre, School of Environment and Life Sciences, University of Salford, Salford, United Kingdom.

${ }^{2}$ Faculty of Biology, Medicine and Health, School of Health Sciences, Division of Pharmacy \& Optometry, University of Manchester, Manchester, United Kingdom.

*Corresponding author:

Luciano Mutti

Biomedical Research Centre,

School of Environment and Life Sciences,

University of Salford,

Salford,

United Kingdom

Email: L.Mutti@salford.ac.uk 


\section{Abstract}

Introduction: Mesothelioma is a rare type of cancer that is strongly tied to asbestos exposure. Despite application of different modalities such as chemotherapy, radiotherapy and surgery, patient prognosis remains very poor and therapies are ineffective. Much research currently focuses on the application of novel approaches such as immunotherapy towards this disease.

Areas Covered: The types, stages and aetiology of mesothelioma are detailed, followed by a discussion of the current treatment options such as radiotherapy, surgery, and chemotherapy. A description of innate and adaptive immunity and the principles and justification of immunotherapy is also included. Clinical trials for different immunotherapeutic modalities are described, and lastly the article closes with an expert commentary and five-year view, the former of which is summarised below.

Expert Commentary: Current efforts for novel mesothelioma therapies have been limited by attempting to apply treatments from other cancers, an approach which is not based on a solid understanding of mesothelioma biology. In our view, the influence of the hostile, hypoxic microenvironment and the gene and metabolic changes that resultantly occur should be characterised to improve therapies. Lastly, clinical trials should focus on overall survival rather than surrogate endpoints to avoid bias and inaccurate reflections of treatment effects.

Keywords: Mesothelioma, immunotherapy, immune checkpoint inhibition, novel therapies, clinical trials, clinical trial endpoints 


\section{Introduction}

Mesothelioma is a general term referring to numerous different cancers that are typically related to asbestos exposure and develop from the normal mesothelial cells that line various organs. Mesothelioma is typically divided into four classifications: pleural mesothelioma (mesothelioma of the lungs); peritoneal mesothelioma (mesothelioma of the abdomen); pericardial mesothelioma (mesothelioma of the heart) and mesothelioma of the tunica vaginalis (testicular mesothelioma) [1,2]. Histologically, there are primarily three broad categories of mesothelioma: epithelioid (approximately $80 \%-90 \%$ of cases); biphasic (approximately 10-20\% of cases) and sarcomatoid (also approximately 10-20\% of cases) [1,3]. Epithelioid mesothelioma is characterised through rounded to cuboidal cells, whilst sarcomatoid mesothelioma is characterised by spindle-shaped cells and cause bulky and aggressive tumours [3]. Lastly, biphasic mesothelioma contains a mixture of sarcomatoid and epithelioid cells. The histological subtype of mesothelioma may be an important determinant of its treatability; although sarcomatoid mesothelioma is relatively rare, it is commonly known as an aggressive cancer and patients have a very poor prognosis [4].

Current treatments for mesothelioma remain ineffective, with no standard second-line therapy and no treatments that significantly improve survival. This therefore represents a significant unmet need, as it is anticipated that the disease will peak between 2015-2030 due to the latency period of the disease [5]. Incidence rates for pleural mesothelioma vary among different countries, with approximately 2000-3000 cases per year in the USA, 1000-1500 cases per year in the UK, and 1000 cases per year in Germany [4]. The latency period between asbestos exposure and disease onset leads to the delayed expected incidence peak, in 
addition to the fact that a quarter of a million deaths are expected from the disease in Europe within the next few years, due to occupational exposure [4].

This review will detail the pathogenesis of mesothelioma, in addition to its stages and the current approaches to treatment, both surgical (tumour resection and palliative care) and pharmacological (drugs such as gemcitabine, pemetrexed and cisplatin). After this, the basics of immunotherapy and its types and potential advantages will be discussed, followed by examples of application of immunotherapy to mesothelioma and current clinical trials. Lastly, the review closes with an Expert Commentary and Five Year View detailing our opinion on mesothelioma treatment and research directions in the present and coming years.

\section{Body}

\subsection{Pathogenesis of Mesothelioma}

Development of mesothelioma is thought to be influenced by a variety of factors such as simian virus 40 (SV40), which has been shown to be present in some human mesothelial tumours. Further evidence for the role of SV40 in mesothelioma development can be seen through the fact that its intracardial injection into mice leads to the development of malignant mesothelioma in $60 \%$ of cases [6]. Other factors indicated as contributing to the development of mesothelioma include genetic susceptibility, in addition to ionising radiation; previous comprehensive reviews have indicated that although a definitive causal link could not be established, the weight of the evidence for prior treatment with or exposure to ionising radiation from different sources was enough to place ionising radiation as a factor to be 
considered $[7,8]$. In addition to this is erionite, a naturally occurring mineral that has properties similar to asbestos [5].

It is widely believed that asbestos exposure is perhaps the most common driver for mesothelioma development, as it has been estimated that approximately $70-80 \%$ of mesothelioma cases are related to occupational or environmental asbestos exposure [4]. It is significantly more probable that men develop the disease rather than women (at a sex ratio of approximately 4:1 - 8:1), again likely due to workplace exposure [9]. It is also recognised that there is a long latency period between asbestos exposure and mesothelioma development (consisting of multiple decades), which has led to the expectation that the disease will peak between 2015-2030 [5].

Asbestos is thought to contribute to mesothelioma development through the inhalation of asbestos fibres, which remain trapped in the lower third of the lung [2]. The unsuccessful clearance of these fibres leads to a chronic inflammatory state which may contribute to mesothelioma development [10]. It has been thought that the release of high-mobility group box 1 protein following induction of necrosis by asbestos exposure may cause a chronic inflammatory state, accumulation of macrophages and TNF $\alpha$ secretion. TNF $\alpha$ then promotes survival of mesothelial cells that have been genetically damaged through asbestos exposure via the activation of NF- $\kappa \mathrm{B}[7,11,12]$. In addition to asbestos alone, concomitant smoking may enhance the risk of developing a malignancy (non-small cell lung cancer) by up to sixtyfold [2].

Despite the above, it is also recognised that not all individuals exposed to asbestos will develop mesothelioma, which implicates a role for the additional factors described above 
such as genetic susceptibility. Further evidence for this is that mesothelioma clustering can be seen within some families [13]. In recent years BRCA1-associated protein 1 (BAP1) germline mutations have been identified as predisposing factors to mesothelioma pathogenesis, with some important differences in clinical outcomes observed between mesothelioma patients with BAP1 mutations, and those without $[9,13]$. In particular, it has been identified that mesothelioma patients with BAP1 mutations have a significantly higher survival (up to seven-fold, irrespective of gender and age) than patients with sporadic mesothelioma [9]. Thus, identification of genetic factors driving mesothelioma development and patient stratification based on these findings may improve patient prognosis and clinical outcomes.

\subsection{Symptoms and Diagnosis of Mesothelioma}

Diagnosis of mesothelioma is complicated by the fact that its symptoms are often nonspecific, as most patients present with a cough, shortness of breath, and difficult, laboured breathing $[2,14]$. Chest pain is also commonly presented, as are pleural effusions and dysphagia (difficulty in swallowing) may also occur, though typically later on the course of the disease. Peritoneal mesothelioma may present symptoms such as nausea, vomiting, loss of appetite and diarrhoea or constipation [14]. Thus, the lack of symptoms specific to the disease makes early diagnosis a difficult task.

In order to effectively diagnose mesothelioma, a combination of pathology insight, examination, radiology and knowledge of the history of the patient's asbestos exposure is required. For patients presenting with pleural effusion, cytological analysis of this may allow confirmation of diagnosis; in one-third of cases pleural fluid is positive for malignant cells 
[14]. However, the presence of malignant cells within pleural fluid alone is usually not enough to confirm diagnosis, and corroboration with clinical, radiological and cytological data is preferred [14]. A pleural biopsy may confirm diagnosis, and a computed tomography (CT) scan can identify the extent of the disease, whilst radiological approaches in general are essential for the diagnosis, staging and management of the disease [14]. Radiological approaches used for the diagnosis of mesothelioma include x-rays, CT scans, magnetic resonance imaging (MRI) scans and positron emission tomography (PET) imaging. The challenge with mesothelioma diagnosis, in addition to the lack of specific symptoms, is the fact that distinguishing malignant tumours from benign pleural diseases can be challenging. However PET imaging has been shown in one study to have $96.8 \%$ sensitivity and $88.5 \%$ specificity in distinguishing malignant from benign pleural disease [14,15].

\subsection{Stages of Mesothelioma}

Various staging protocols have been established for mesothelioma development, usually for malignant pleural mesothelioma (MPM) as there is a lack of staging for other mesothelioma types [2]. Examples of staging protocols include the Butchart system (based on the spread of the disease irrespective of histology) and the Brigham system (based on surgical resectability and involvement of lymph nodes), however the most widespread staging system in terms of usage is that developed by the International Mesothelioma Interest Group (IMIG), which is more detailed and incorporates information on the tumour, node involvement, and metastasis $[2,14,16]$.

Stage I MPM under the staging system developed by the IMIG includes lymph node-negative patients with minimal visceral pleural involvement and minimal tumour growth restricted to 
the parietal pleura, whilst Stage II MPM is lymph node-negative and confluent superficial tumour growth on all pleural surfaces or involvement of the lung parenchyma or diaphragm [16]. Stage III, which represents the most common stage of disease presentation, consists of tumours which have metastasised to areas such as lymph nodes, or whose tumour has extended into the soft tissues of areas such as the chest well or pericardium. Lastly, Stage IV MPM contains features such as locally advanced tumours invading the spine or ribs and patients may present with distant metastases [16]. A CT-PET staged series demonstrated that $3 \%$ of patients presented with Stage I, $9 \%$ Stage II, $48 \%$ Stage III and $40 \%$ at Stage IV [17]. The stage at which mesothelioma is diagnosed can have important implications for its treatability, as detailed in the next section.

\subsection{Current Treatments for Mesothelioma}

Mesothelioma may be treated through combination or individual application of radiotherapy, chemotherapy, and surgery. The stage of the disease is an important determinant of which approach to use, with earlier stages being generally more treatable and potentially resectable by surgery.

\subsubsection{Palliative and Curative Treatments for Mesothelioma}

Regrettably, current treatments for mesothelioma do not significantly prolong survival, and there is no standard second-line therapy. However, there are established treatments and therapeutic options which are broadly split into palliative care (to provide relief from symptoms and alleviate patient suffering) and curative treatments (to treat and eliminate the actual disease). Suggested criteria to stratify patients to curative treatments or palliative care 
have been described, such as the decision to employ palliative care if the patient has a poor nutritional state and general condition, Stage III or IV mesothelioma, or biphasic or sarcomatoid mesothelioma regardless of its stage [18]. As previously described, sarcomatoid mesothelioma is especially difficult to treat and its patients have a very poor prognosis [4]. Converse to the justifications for palliative therapy, treatment with a curative intent may be undertaken if the patient is younger than seventy years old, has no significant cardiopulmonary compromise, has epithelioid mesothelioma and has no relevant accompanying disease [18].

\subsubsection{Surgical Treatment of Mesothelioma}

Surgery may be employed as either palliative care or used with curative intent. Generally, curative surgery is attempted only for resectable tumours, which are generally Stage I or Stage II. Although the ideal result from surgery would be a complete removal of the tumour, this is applicable only for a minority of patients as over $80 \%$ of mesothelioma diagnoses occur in Stage III or IV $[16,19,20]$. Thus, surgery is generally employed as palliative care, with the aim being cytoreduction of the tumour mass to alleviate symptoms. Surgery may be employed individually for patients with resectable tumours, however it is generally combined with other therapeutic modalities such as chemotherapy or radiotherapy, as it has been shown that patients undergoing multimodality therapy had a median survival of twenty months against ten for surgery alone [21].

\subsubsection{Chemotherapy for Mesothelioma}


Despite the relatively poor efficacy and clinical outcome, chemotherapy is employed for the treatment of mesothelioma, as some improvements in survival have been observed [4]. The cornerstone of chemotherapy for the treatment of mesothelioma is combination chemotherapy, due to the fact that combination chemotherapy generally leads to better therapeutic outcomes than single agent chemotherapy. Anti-folates (such as pemetrexed) are often used in conjunction with platinum-based therapy (such as cisplatin) as a first-line therapy for unresectable advanced-stage MPM, however there is no standard second-line therapy for patients who do not respond to this [22,23]. Other drugs, including gemcitabine, etoposide and doxorubicin have also been used for the treatment of mesothelioma, however outcomes remain poor as median survival for patients treated chemotherapy after diagnosis is only four to twelve months $[3,24]$. Thus, surgery and chemotherapy, which are the cornerstones for treatment in other cancer types, are both of limited use in mesothelioma and therefore new approaches are urgently needed.

\subsection{Immunity and Immunotherapy}

\subsubsection{Innate and Adaptive Immunity}

Protective mechanisms within the human body may generally be divided into innate or adaptive. Innate immunity is the first-line response to a pathogen but cannot provide longterm protection, and may generally be through anatomic or chemical barriers, in addition to cellular responses [25]. Examples of anatomical barriers include the epithelial skin surfaces and glandular and mucosal surface, whilst examples of chemical barriers include antimicrobial substances such as lysozyme within acidic environments [25]. Cellular-based innate immunity requires either recognition of conserved molecular components on the 
surface of the pathogen, or recognition of intracellular receptors within the pathogen. These conserved molecular components are generally referred to as pathogen-associated molecular patterns (PAMPS) and cells such as dendritic cells (DCs), macrophages, neutrophils and monocytes recognise the PAMPS and through phagocytosis remove pathogens [25].

In addition to the cells listed previously, natural killer (NK) cells are also involved in innate immunity, providing protection through surveillance and detecting cells infected with viruses. Additionally, NK cells may target tumour cells or other normal cells through their lack of major histocompatibility complex (MHC) molecules, and can be activated through interleukin stimulation such as interleukin-2 (IL-2) treatment $[25,26]$. DCs also serve as a link between innate and adaptive immunity through two broad mechanisms. First, DCs are "sentinels" and capture, process and present antigens and migrate to lymphoid tissue to select uncommon T cells that react to the antigen. Secondly, DCs are "sensors" and thus respond to numerous environmental stimuli via differentiation or maturation [27]. NK cells have also been shown to serve as a bridge of sorts through the promotion of cross-presentation of tumour-derived antigens by DCs through the release of interferon-gamma (IFN $\gamma$ ) and tumour necrosis factor alpha (TNF $\alpha$ ) which ultimately promotes antigen-specific CD8+ T cell (also known as cytotoxic T lymphocytes) activation [25,28].

Unlike innate immunity, adaptive immunity confers long-lasting protection against infectious agents through recognition and memory of specific antigens. Whilst innate immunity relies on the recognition of highly repetitive molecules, adaptive immunity instead requires recognition of specific antigens [25]. Adaptive immunity is dependent on receptors that are custom made based on recombination of gene segments and involves T lymphocytes, which mature in the thymus and are responsible for effecting cellular immune responses, and B 
lymphocytes, which are responsible for producing antibodies [29]. Mature T cells are activated following interaction between their T cell receptor (TCR) with antigenic peptides in complex with MHC molecules on antigen-presenting cells (APCs), with CD8+ T cells recognising MHC Class I molecules whilst CD4+ T cells (also called T helper cells) recognise MHC Class II molecules [29]. CD8+ T cells comprise the majority of circulating T cells and thus serve to remove cells harbouring pathogens such as viruses and transformed cells, whilst CD4+ cells produce cytokines that assist in the activity of other T cells [29]. Thus, innate and adaptive immunity together provide a robust defence for the body against pathogens and harmful cells.

\subsubsection{Immunotherapy}

Of all the new therapeutic modalities under investigation for cancer treatment, immunotherapy is one that has received significant attention $[5,30]$. Immunotherapy is an innovative approach that, rather than targeting cancer cells themselves via drug treatment, aims to stimulate the immune system to promote an anti-tumour immune effect [31]. Specific to MPM, the potential application of immunotherapy may be sound given that it has been shown that lymphocyte infiltration within the tumour mass correlated with improved patient prognosis $[32,33]$

Immunotherapy as a whole may be largely split into active immunotherapy and passive immunotherapy [34]. The difference lies in whether the immune system of the patient is stimulated in situ; passive immunotherapy generally isolates effectors in vitro before applying them to the patient, whilst active immunotherapy aims to stimulate the patient's own immune system, primarily through vaccination [34]. It has been stated previously that a 
common shortcoming of passive immunotherapy is that it is likely to yield only a temporary benefit, whilst active immunotherapeutic strategies may offer long-term disease control through education of the host's immune system [35]. Passive immunotherapy may typically be used when the patient's immune system is weak or poorly responsive, whilst active immunotherapy requires that the patient's immune system is responsive to challenge, will be competently stimulated and promote effector actions [36].

There are many types of active and passive immunotherapy (Figure 1) [36]. Examples of active immunotherapeutic approaches include vaccination (such as peptide-based and DCbased), immune checkpoint inhibition and oncolytic viruses, whilst examples of passive immunotherapeutic approaches tumour-specific monoclonal antibodies (mAbs), cytokine administration, and adoptive cell transfer [36]. Numerous different immunotherapeutic approaches have been applied to mesothelioma, detailed below in the relevant subsections.

\subsection{Application of Active Immunotherapy to Mesothelioma}

\subsubsection{Immunotherapeutic Vaccination}

Immunotherapeutic vaccination aims to induce tumour-specific immune responses in vivo and there are multiple types such as peptide vaccination (the most common) or DC-based vaccines [36]. Peptide vaccines contain immunogenic epitopes from tumour-specific or tumour-associated antigens (TSAs or TAAs respectively), which can arise from numerous sources including but not limited to mutated oncogenes or tumour suppressor genes, oncofoetal proteins, oncogenic viruses, cancer-testis antigens or overexpressed self-proteins [36]. It is thought that immunogenic recognition of these TSAs/TAAs can lead to specific 
immune responses against the tumour, hence why it is such an attractive prospect. This is particularly relevant for personal peptide-based vaccination (PPV) as it is based on the concept of strengthening the host's existing immune response.

DCs represent an ideal "vehicle" for cancer vaccines due to their ability to affect both the innate and adaptive immune responses, and DC-based vaccination primarily works through two approaches: in vivo direct targeting of antigens to DC receptors, and ex vivo generation of antigen-loaded DCs [36]. DC-based vaccination is an approach that remains under a significant degree of investigation, due to the long-held interest and potential of the approach. One method that has garnered particular interest is the use of autologous tumour cells as a source for TAAs, as theoretically they should provide the most comprehensive coverage of tumour-specific components available. Allogenic tumour cells are also useful in providing TAAs through their continuing culture in vitro and thus may theoretically provide limitless TAAs and allow for large-scale production of vaccines that can be consistent between vaccine batches thus allowing for improved comparison of clinical outcomes [36]. Autologous tumour cell vaccination requires transfection of tumour cells to produce cytokines and co-stimulatory molecules followed by irradiation of the tumour cells. Irradiation of the tumour cells renders them inactive and thus their injection into patients is safe as the cells do not proliferate and present TAAs to T cells, thus promoting a tumourspecific immune response [36].

Specific to mesothelioma, one frequently investigated protein is Wilms tumor 1 (WT1) due to the fact that it is overexpressed in MPM and immunohistochemical staining of WT1 is routinely used to aid in MPM diagnosis [37]. Numerous clinical trials of immunotherapeutic vaccination relating to mesothelioma have been performed, with examples listed in Table 1. 
Within the healthy body, the immune system is tightly regulated both positively and negatively to ensure an appropriate immune response. Among these regulatory elements, immune checkpoints comprise a number of inhibitory pathways that serve as a way to maintain self-tolerance and minimise immune-mediated damage through modulating the length and strength of the response [44]. However, it is now apparent that this regulation is hijacked during the process of carcinogenesis and aberrantly regulated to allow cancer cells to evade immune detection. Cytotoxic T-lymphocyte-associated antigen 4 (CTLA4) and programmed cell death protein 1 (PD1) are two key negative regulators of the immune system and thus their blockage through antibodies or other treatments is currently under a significant degree of investigation as it is thought that if their expression is reduced, immunemediated tumour death could be enhanced (Figure 2) [44].

Immune checkpoint blockade has shown success in some other cancer types such as melanoma, where blockage of CTLA4 through ipilimumab (a mAb against CTLA4) has been approved for its treatment [20]. Similar to ipilimumab is tremelimumab, another mAb against CTLA4, which remains under investigation in many clinical trials though it is not yet approved for use in the clinic [5]. After the success of CTLA4 inhibition, the effects of PD1 inhibition (through either targeting PD1 itself or its ligands) have also been assessed in clinical trials and currently pembrolizumab and nivolumab are approved for the treatment of metastatic melanoma $[32,45]$.

Despite the application of immune checkpoint blockade in melanoma, these outcomes have not transferred to mesothelioma. One of the biggest trials for immune checkpoint blockade in 
mesothelioma was DETERMINE, which as of data presented at ASCO 2016 consisted of 571 patients randomised to either placebo $(n=189)$ or treated with tremelimumab $(n=382)$ as a second- or third-line therapy [46]. The results for this trial presented at ASCO 2016 showed that $81 \%$ of patients died, whilst no statistically significant difference in overall survival between treated (median=7.7 months) and placebo (median 7.3 months) was observed [46]. The most frequent adverse events included diarrhoea, decreased appetite, dyspnoea, fatigue and nausea [46]. Results for PD1 inhibition initially appeared more promising; preliminary results for KEYNOTE-028, a trial assessing pembrolizumab in PD1-positive mesothelioma patients demonstrated a disease control rate of $76 \%$ and the drug was generally well tolerated [47]. Updated results (published May 2017) confirmed that the drug appeared to be well tolerated, indicated that pembrolizumab "might confer anti-tumour activity in patients with PD-L1-positive malignant pleural mesothelioma" and suggested that further investigations were warranted [48]. There are many other trials that have been completed or are ongoing using different immune checkpoint inhibitors in mesothelioma (Table 2).

\subsubsection{Oncolytic Virotherapy}

Oncolytic viruses are either genetically engineered or naturally occurring viruses that preferentially target tumour cells over healthy cells. In addition to this, they are capable of impairing abnormal vasculature and promote immune functions. Due to its potential, this approach has garnered increased interest in recent years, though questions over issues such as administration routes and the injection frequency required to achieve a therapeutic effect and theorising how the oncolytic viruses may evade immune detection remain [52]. Despite these issues, the challenging clinical management of diseases such as mesothelioma makes such diseases suitable candidates for innovative therapies. Particularly for MPM, treatment of 
pleural effusions requires access to the pleural cavity, and thus local injections of oncolytic viruses is a possibility [52].

The application of oncolytic virotherapy to the treatment of mesothelioma has been comprehensively reviewed by Boisgerault and colleagues in 2015 [52]. There are numerous types of oncolytic viruses such as herpesvirus, adenovirus and RNA viruses. An ongoing Phase I/II study sponsored by Virttu Biologics Limited (ClinicalTrials.gov identifier NCT01721018) is assessing the effect of intrapleural administration of HSV1716, a mutated herpes simplex virus. 12 MPM patients have been enrolled but the study's results have not been posted yet (estimated completion is June 2017). Multiple trials have been initiated or are completed relating to virotherapy in mesothelioma (summarised in Table 1 in the manuscript by Boisgerault and colleagues [52]). A new Phase I/II trial (registered July 2016, ClinicalTrials.gov identifier NCT02879669) aims to assess the effects of ONCOS-12, an oncolytic adenovirus that primes the immune system in the treatment of unresectable MPM. The study aims to recruit 30 patients and its expected primary completion date is December 2018. Another new Phase I study (registered March 2016, ClinicalTrials.gov identifier NCT02714374) aims to investigate GL-ONC1, a genetically modified vaccinia virus that may have an anti-tumour effect. The study aims to recruit 36 patients with solid tumours and has an estimated primary completion date of March 2018, with the overall study being completed in March 2020. Thus, in addition to the numerous trials described by Boisgerault and colleagues [52], trials remain ongoing and therefore oncolytic virotherapy is still under a degree of investigation.

\subsection{Application of Passive Immunotherapy to Mesothelioma}


Cytokine administration was among the first therapeutic interventions in the treatment of cancer, though its use as a monotherapy has fallen significantly out of favour and it is now generally used in combination therapy [36]. Cytokine administration aims to provide a shortterm "boost" to anti-tumour effects through temporary stimulation of the host's immune system [32]. Numerous cytokines are utilised for this [36] but a common one is interleukin-2 (IL2). An early Phase II study with intrapleural IL2 administration with 22 mesothelioma patients indicated that there may be some beneficial effects of cytokine administration, with median survival of responders (28 months) being significantly longer than the median survival for non-responders ( 8 months) [53,54]. However, this initial positive result was hampered by further research and trials which demonstrated high treatment-related toxicity and side effects [54].

Despite the apparent failure of IL2 administration as a monotherapy, it is currently under investigation as part of multimodality therapy. A study sponsored by the University Health Network, Toronto is currently recruiting participants for a Phase I/II study that aims to examine the effect of tumour-infiltrating lymphocytes and low-dose IL2 therapy in pleural mesothelioma patients following treatment with cyclophosphamide and fludarabine. The study (ClinicalTrials.gov identifier NCT02414945) aims to recruit ten patients and has an estimated completion of November 2025.

\subsubsection{Monoclonal Antibody Therapy}


The overarching principle behind the use of mAbs in cancer therapy is to target cancerspecific or cancer-associated antigens which the antibody binds to, ultimately resulting in an anti-tumour effect through a variety of mechanisms [36]. For mesothelioma, common antibody targets include mesothelin (highly expressed in mesothelioma) and TGF- $\beta$ [32]. Monoclonal antibodies may be combined with other therapeutics to serve, for example, as vehicles for drugs.

Mesothelin represents an interesting target as its high level of expression in mesothelioma results in it commonly being used as a serum biomarker for mesothelioma diagnosis [55] and thus there are several trials investigating its potential as a biomarker. Comparatively, TGF- $\beta$ is an interesting protein as in normal epithelial cells it is a potent growth inhibitor and promotes cellular differentiation. However, in the case of tumour progression, cancer cells lose their ability to respond to TGF- $\beta$ and thus TGF- $\beta$ becomes a key stimulator of angiogenesis, affects the microenvironment and causes immunosuppression [56]. Mesothelin and TGF- $\beta$ are both thus interesting targets and there are numerous trials targeting them, with some examples of initiated, ongoing or completed trials listed in Table 3. 


\subsubsection{Adoptive Cell Transfer}

Adoptive cell transfer is a strategy that primarily relies on immune cells that have been "educated" ex vivo before the application of these autologous cells to the patient. The application of adoptive cell transfer through cells such as tumour-infiltrating lymphocytes represents a promising therapeutic strategy as it is backed by preclinical support and the autologous nature of the approach may improve its efficacy $[61,62]$. Education of these $T$ cells may be via the transfection or transduction of chimeric antigen receptors (CARs) to the T cells, which allows the T cell to recognise tumour cells expressing TSAs or TAAs [54]. Frequent targets for adoptive cell transfer include fibroblast activation protein (FAP) and the aforementioned mesothelin [54]. Numerous trials relating to adoptive cell transfer in mesothelioma have been initiated, are ongoing or are completed, with examples listed below in Table 4.

\section{Conclusions}

The "orphan" status of mesothelioma in terms of the lack of beneficial treatments creates a pressing need to uncover novel therapeutics to improve the outcomes for this disease whose incidence peak is anticipated to occur in the coming years. The fact that therapies proven effective for multiple other cancer types such as tyrosine kinase inhibition have demonstrated little therapeutic benefit other than bevacizumab for newly-diagnosed mesothelioma is surprising and indicates mesothelioma as a particularly aggressive or unique tumour.

Innovative approaches such as immunotherapy have been successfully applied and approved in other cancer types, leading to the investigation of such approaches in mesothelioma, as is 
apparent from the large number of clinical trials that have been initiated, are ongoing, or are completed. Although there has been a significant degree of hope for the role of immunotherapy as a treatment for mesothelioma, clinical trial results remain largely disappointing. Immunotherapy for mesothelioma is likely complicated by the chronic inflammatory state that drives mesothelioma development. Different approaches to immunotherapy - whether passive approaches such as cytokine administration or active approaches such as immune checkpoint blockade - have demonstrated relatively high levels of treatment-related adverse events and the therapeutic benefit remains unclear.

Despite the negative outcomes of numerous trials, it is clear that there are many approaches under investigation at different clinical trial phases. It is hoped that these investigations could yield a therapeutic benefit to alleviate the suffering of mesothelioma patients, though in addition to monitoring effects on survival (particularly overall instead of progression-free) the degree and frequency of treatment-related adverse events should be carefully monitored.

\section{Expert Commentary}

In recent years there has been an increased interest in developing improved therapeutics for the treatment of mesothelioma. Although undoubtedly welcome, efforts have been focussed largely on applying existing therapies from other cancers such as immune checkpoint blockade or tyrosine kinase inhibition to mesothelioma. Though such approaches have promoted improved clinical outcomes in numerous cancer types, such success has generally not been seen in mesothelioma, with most clinical trials reporting negative results. 
It is therefore our opinion that the development of novel therapeutics should focus not on applying therapies from other cancers, but should instead be based on a detailed understanding of the specific factors driving the carcinogenesis and resistance of mesothelioma. In particular, it is widely established that the hypoxic microenvironment of mesothelioma can have significant influence on the gene expression profile of mesothelioma cells, with microenvironment constituents such as stromal cells playing key roles in this.

The chronic inflammation that drives mesothelioma leads to an altered immune response, which may partially explain the general lack of efficacy of immunotherapy. Similarly, the low mutational load of mesothelioma relative to other cancer types presents an additional explanation for potential reasons for therapy failure. If one also considers the difficulty to apply the immune-related response criteria to MPM and the rate and degree of side effects it is obvious that particular caution is needed before drawing conclusions. Although many trials for immunotherapeutic modalities have shown failure or limited benefit, some results from pembrolizumab still need to be validated in randomized clinical trials aiming to assess its real impact on the overall survival of patients.

Examination of the mechanisms that mesothelioma cells use to survive within their hostile microenvironment and tolerate the gene and metabolic changes that occur should be examined in detail, as elucidation of these mechanisms may provide "druggable" targets in addition to insight into altered pathways driving mesothelioma development. In our view, 3D tissue culture models such as organoids, accurate in vitro simulation of the microenvironment and immune system, and lastly the use of primary cells wherever possible will all facilitate our improved understanding of factors contributing towards the carcinogenesis of mesothelioma. 
It has recently been demonstrated that surrogate end points for clinical trials such as progression-free survival do not fully reflect overall survival for immunotherapy trials and may often be significantly different [63]. Caution has therefore been advised when analysing results containing only progression-free survival and not overall survival data. Future trials should aim to include information on overall survival wherever possible so as to provide the most comprehensive information available.

Ultimately, despite the fact that mesothelioma is still very much an orphan disease, there has been an increased interest in recent years and we hope that this increased interest will eventually lead to improved therapies and clinical outcomes for patients. By achieving a precise understanding of mesothelioma carcinogenesis we may be able to isolate essential factors and thus identify potential routes for the development of novel therapeutics.

\section{Five-Year View}

Immunotherapy remains highly investigated across numerous different diseases, including mesothelioma, likely due to the success of the approach in diseases such as melanoma. Although approaches such as interleukin-2 have demonstrated a therapeutic effect, these benefits are limited through treatment-related toxicity and side effects. Similarly, although immune checkpoint blockade remains highly investigated, results for mesothelioma have been disappointing.

We anticipate that in the coming years immunotherapy will continue to be investigated due the high number of clinical trials (detailed in the tables of this article) that are in the 
recruitment or pre-recruitment stages. As suggested by Thapa and colleagues, it may be worth uncovering the biology behind immune checkpoints other than PD1 and CTLA4 and developing clinical trials for inhibitors against them as these under-investigated targets may represent novel therapeutic avenues [54].

Researching immunotherapy should take into consideration the role of the microenvironment as it is readily apparent that hypoxia and the chronic inflammation that defines mesothelioma leads to an altered immune response. Both of these factors are under increased investigation and we anticipate that elucidation of these factors may alter and improve research focus.

Lastly, the recent argument that surrogate endpoints (such as progression-free survival) do not fully reflect the endpoint of overall survival in terms of treatment effect size [63] may promote an altered approach to trials, by aiming to report overall survival and base conclusions on this rather than potentially misleading surrogate endpoints.

\section{Key Issues}

- Mesothelioma is a rare, aggressive cancer whose incidence is expected to peak in the coming years

- Current treatments do not significantly prolong survival, and clinical outcomes remain poor

- Immunotherapy is a widely-investigated approach that aims to utilise the patient's own immune system against tumours 
- Numerous immunotherapeutic approaches such as peptide, DC-based and autologous or allogenic vaccination, immune checkpoint blockade and cytokine administration exist

- Although immune checkpoint blockade has shown effect in melanoma, this approach has demonstrated a very limited benefit in mesothelioma

- In addition to monitoring of overall survival instead of progression-free survival or other surrogate endpoints, side effects of immunotherapeutic approaches should also be considered

- Research appears to rule out immunotherapy as a single agent modality, but further research may create a position for it as an adjuvant with other treatments

\section{Funding}

This manuscript has not been funded.

\section{Declaration of interest}

The authors have no relevant affiliations or financial involvement with any organization or entity with a financial interest in or financial conflict with the subject matter or materials discussed in the manuscript. This includes employment, consultancies, honoraria, stock ownership or options, expert testimony, grants or patents received or pending, or royalties. 


\section{References}

*Paper of interest

**Paper of considerable interest

1. Inai K. Pathology of mesothelioma. Environmental Health and Preventive Medicine, 13(2), 60-64 (2008).

2**. Mott FE. Mesothelioma: A Review. The Ochsner Journal, 12(1), 70-79 (2012).

Highly useful overview of mesothelioma by Mott.

3. Nabavi N, Bennewith KL, Churg A, Wang Y, Collins CC, Mutti L. Switching off malignant mesothelioma: exploiting the hypoxic microenvironment. Genes \& Cancer, 7(1112), 340-354 (2016).

4. Mutti L. Malignant pleural mesothelioma: new ideas needed. Lung Cancer Management, 4(5), 201-203 (2015).

5. Guazzelli A, Bakker E, Krstic-Demonacos M, Lisanti MP, Sotgia F, Mutti L. AntiCTLA-4 therapy for malignant mesothelioma. Immunotherapy, 9(3), 273-280 (2017).

6. Rivera Z, Strianese O, Bertino P, Yang H, Pass H, Carbone M. The relationship between simian virus 40 and mesothelioma. Current opinion in pulmonary medicine, 14(4), 316-321 (2008).

7. Carbone M, Ly BH, Dodson RF et al. Malignant Mesothelioma: Facts, Myths and Hypotheses. Journal of cellular physiology, 227(1), 44-58 (2012).

8. Goodman JE, Nascarella MA, Valberg PA. Ionizing radiation: a risk factor for mesothelioma. Cancer causes \& control : CCC, 20(8), 1237-1254 (2009).

9. Baumann F, Flores E, Napolitano A et al. Mesothelioma patients with germline BAP1 mutations have 7-fold improved long-term survival. Carcinogenesis, 36(1), 76-81 (2015). 
10. Linton A, van Zandwijk N, Reid G, Clarke S, Cao C, Kao S. Inflammation in malignant mesothelioma - friend or foe? Annals of Cardiothoracic Surgery, 1(4), 516-522 (2012).

11. Yang H, Bocchetta M, Kroczynska B et al. TNF-alpha inhibits asbestos-induced cytotoxicity via a NF-kappaB-dependent pathway, a possible mechanism for asbestosinduced oncogenesis. Proceedings of the National Academy of Sciences of the United States of America, 103(27), 10397-10402 (2006).

12. Yang H, Rivera Z, Jube S et al. Programmed necrosis induced by asbestos in human mesothelial cells causes high-mobility group box 1 protein release and resultant inflammation. Proceedings of the National Academy of Sciences of the United States of America, 107(28), 12611-12616(2010).

13. Testa JR, Cheung M, Pei J et al. Germline BAP1 mutations predispose to malignant mesothelioma. Nature genetics, 43(10), 1022-1025 (2011).

14. Moore AJ, Parker RJ, Wiggins J. Malignant mesothelioma. Orphanet Journal of Rare Diseases, 3(1), 34 (2008).

15. Duysinx B, Nguyen D, Louis R et al. Evaluation of pleural disease with 18fluorodeoxyglucose positron emission tomography imaging. Chest, 125(2), 489-493 (2004). 16**. Ismail-Khan R, Robinson LA, Williams CC, Jr., Garrett CR, Bepler G, Simon GR. Malignant pleural mesothelioma: a comprehensive review. Cancer control : journal of the Moffitt Cancer Center, 13(4), 255-263 (2006).

\section{Very comprehensive information on mesothelioma in general by Ismail-Khan and colleagues.}

17. Fennell DA, Gaudino G, O'Byrne KJ, Mutti L, van Meerbeeck J. Advances in the systemic therapy of malignant pleural mesothelioma. Nature clinical practice. Oncology, 5(3), 136-147 (2008). 
18. Neumann V, Loseke S, Nowak D, Herth FJ, Tannapfel A. Malignant pleural mesothelioma: incidence, etiology, diagnosis, treatment, and occupational health. Deutsches Arzteblatt international, 110(18), 319-326 (2013).

19. Belli C, Fennell D, Giovannini M, Gaudino G, Mutti L. Malignant pleural mesothelioma: current treatments and emerging drugs. Expert opinion on emerging drugs, 14(3), 423-437 (2009).

20. Guazzelli A, Hussain M, Krstic-Demonacos M, Mutti L. Tremelimumab for the treatment of malignant mesothelioma. Expert opinion on biological therapy, 15(12), 1819$1829(2015)$

21. Flores RM, Zakowski M, Venkatraman E et al. Prognostic factors in the treatment of malignant pleural mesothelioma at a large tertiary referral center. $J$ Thorac Oncol, 2(10), 957965 (2007).

22. Pinton G, Manente AG, Tavian D, Moro L, Mutti L. Therapies currently in Phase II trials for malignant pleural mesothelioma. Expert opinion on investigational drugs, 22(10), $1255-1263$ (2013).

23. Remon J, Reguart N, Corral J, Lianes P. Malignant pleural mesothelioma: new hope in the horizon with novel therapeutic strategies. Cancer treatment reviews, 41(1), 27-34 (2015).

24. Bertino P, Porta C, Barbone D et al. Preliminary data suggestive of a novel translational approach to mesothelioma treatment: imatinib mesylate with gemcitabine or pemetrexed. Thorax, 62(8), 690-695 (2007).

25*. Berger MS, Weller M. Gliomas (Elsevier Science, 2016).

Chapter 10 of Berger's book ("Principles of Immunotherapy") provides a detailed overview of immunity and immunotherapeutic approaches. 
26. Bix M, Liao NS, Zijlstra M, Loring J, Jaenisch R, Raulet D. Rejection of class I MHC-deficient haemopoietic cells by irradiated MHC-matched mice. Nature, 349(6307), 329-331 (1991).

27. Steinman RM. Linking innate to adaptive immunity through dendritic cells. Novartis Foundation symposium, 279, 101-109; discussion 109-113, 216-109 (2006).

28. Deauvieau F, Ollion V, Doffin AC et al. Human natural killer cells promote crosspresentation of tumor cell-derived antigens by dendritic cells. International journal of cancer, 136(5), 1085-1094 (2015).

29. Bonilla FA, Oettgen HC. Adaptive immunity. The Journal of allergy and clinical immunology, 125(2 Suppl 2), S33-40 (2010).

\section{Detailed article on Adaptive Immunity by Bonilla and colleagues.}

30. Bograd AJ, Suzuki K, Vertes E et al. Immune responses and immunotherapeutic interventions in malignant pleural mesothelioma. Cancer Immunology, Immunotherapy, 60(11), 1509-1527 (2011).

31. Farkona S, Diamandis EP, Blasutig IM. Cancer immunotherapy: the beginning of the end of cancer? BMC Medicine, 14(1), 73 (2016).

32. Bakker E, Guazzelli A, Krstic-Demonacos M, Lisanti M, Sotgia F, Mutti L. Current and prospective pharmacotherapies for the treatment of pleural mesothelioma. Expert Opinion on Orphan Drugs, null-null (2017).

33. Leigh RA, Webster I. Lymphocytic infiltration of pleural mesothelioma and its significance for survival. South African medical journal = Suid-Afrikaanse tydskrif vir geneeskunde, 61(26), 1007-1009 (1982).

34. Grégoire M. What's the place of immunotherapy in malignant mesothelioma treatments? Cell Adhesion \& Migration, 4(1), 153-161 (2010). 
35. Hegmans JP, Hemmes A, Aerts JG, Hoogsteden HC, Lambrecht BN. Immunotherapy of murine malignant mesothelioma using tumor lysate-pulsed dendritic cells. Am J Respir Crit Care Med, 171(10), 1168-1177 (2005).

36. Papaioannou NE, Beniata OV, Vitsos P, Tsitsilonis O, Samara P. Harnessing the immune system to improve cancer therapy. Annals of Translational Medicine, 4(14) (2016).

37. Krug LM, Dao T, Brown AB et al. WT1 peptide vaccinations induce CD4 and CD8 T cell immune responses in patients with mesothelioma and non-small cell lung cancer. Cancer immunology, immunotherapy : CII, 59(10), 1467-1479 (2010).

38. Maslak PG, Dao T, Krug LM et al. Vaccination with synthetic analog peptides derived from WT1 oncoprotein induces T-cell responses in patients with complete remission from acute myeloid leukemia. Blood, 116(2), 171-179 (2010).

39. Hegmans JP, Veltman JD, Lambers ME et al. Consolidative dendritic cell-based immunotherapy elicits cytotoxicity against malignant mesothelioma. Am J Respir Crit Care Med, 181(12), 1383-1390 (2010).

40. Berneman ZN, Germonpre P, Huizing MT et al. Dendritic cell vaccination in malignant pleural mesothelioma: A phase I/II study. In: 2014 ASCO Annual Meeting. (Ed.^(Eds) (Chicago, USA, 2014)

41. Cornelissen R, Hegmans JP, Maat AP et al. Extended Tumor Control after Dendritic Cell Vaccination with Low-Dose Cyclophosphamide as Adjuvant Treatment in Patients with Malignant Pleural Mesothelioma. Am J Respir Crit Care Med, 193(9), 1023-1031 (2016).

42. Aggarwal C, Haas AR, Metzger S et al. Phase I study of gene mediated cytotoxic immunotherapy (GMCI) for patients with malignant pleural effusion (MPE). In: 2016 ASCO Annual Meeting. (Ed.^(Eds) (Chicago, USA, 2016)

43. Weber JS, Vogelzang NJ, Ernstoff MS et al. A Phase 1 Study of a Vaccine Targeting Preferentially Expressed Antigen in Melanoma and Prostate-specific Membrane Antigen in 
Patients With Advanced Solid Tumors. Journal of immunotherapy (Hagerstown, Md. : 1997), 34(7), 556-567 (2011).

44*. Pardoll DM. The blockade of immune checkpoints in cancer immunotherapy. Nat Rev Cancer, 12(4), 252-264 (2012).

\section{Comprehensive review of immune checkpoint blockade by Pardoll.}

45. Chuk MK, Chang JT, Theoret MR et al. FDA Approval Summary: Accelerated Approval of Pembrolizumab for Second-Line Treatment of Metastatic Melanoma. Clin Cancer Res, (2017).

46. Kindler HL, Scherpereel A, Calabrò L et al. Tremelimumab as second- or third-line treatment of unresectable malignant mesothelioma (MM): Results from the global, doubleblind, placebo-controlled DETERMINE study. In: 2016 ASCO Annual Meeting. (Ed.^(Eds) (Chicago, USA, 2016)

47. Alley EW, Molife LR, Santoro A et al. Abstract CT103: Clinical safety and efficacy of pembrolizumab (MK-3475) in patients with malignant pleural mesothelioma: Preliminary results from KEYNOTE-028. Cancer Research, 75(15 Supplement), CT103-CT103 (2015). 48. Alley EW, Lopez J, Santoro A et al. Clinical safety and activity of pembrolizumab in patients with malignant pleural mesothelioma (KEYNOTE-028): preliminary results from a non-randomised, open-label, phase 1b trial. The Lancet. Oncology, 18(5), 623-630 (2017).

49. Calabro L, Morra A, Fonsatti E et al. Efficacy and safety of an intensified schedule of tremelimumab for chemotherapy-resistant malignant mesothelioma: an open-label, singlearm, phase 2 study. The Lancet. Respiratory medicine, 3(4), 301-309 (2015).

50. Calabro L, Morra A, Fonsatti E et al. Tremelimumab for patients with chemotherapyresistant advanced malignant mesothelioma: an open-label, single-arm, phase 2 trial. The Lancet. Oncology, 14(11), 1104-1111 (2013). 
51. Kelly K, Heery CR, Patel MR et al. Avelumab (MSB0010718C; anti-PD-L1) in patients with advanced cancer: safety data from 1300 patients enrolled in the phase $1 \mathrm{~b}$ JAVELIN Solid Tumor trial. In: 2016 ASCO Annual Meeting. (Ed.^(Eds) (Chicago, USA, 2016)

52. Boisgerault N, Achard C, Delaunay T et al. Oncolytic virotherapy for human malignant mesothelioma: recent advances. Oncolytic Virotherapy, 4, 133-140 (2015). 53. Astoul P, Picat-Joossen D, Viallat JR, Boutin C. Intrapleural administration of interleukin-2 for the treatment of patients with malignant pleural mesothelioma: a Phase II study. Cancer, 83(10), 2099-2104 (1998).

54**. Thapa B, Watkins DN, John T. Immunotherapy for malignant mesothelioma: reality check. Expert review of anticancer therapy, 1-10 (2016).

Very recent review on immunotherapy in mesothelioma that has a different focus to this review by Thapa and colleagues.

55. Hollevoet K, Reitsma JB, Creaney J et al. Serum mesothelin for diagnosing malignant pleural mesothelioma: an individual patient data meta-analysis. J Clin Oncol, 30(13), 15411549 (2012).

56. Stevenson JP, Kindler HL, Papasavvas E et al. Immunological effects of the TGF $\beta$ blocking antibody GC1008 in malignant pleural mesothelioma patients. Oncoimmunology, 2(8), e26218 (2013).

57. Hassan R, Cohen SJ, Phillips M et al. Phase I Clinical Trial of the Chimeric AntiMesothelin Monoclonal Antibody MORAb-009 in Patients with Mesothelin Expressing Cancers. Clinical cancer research : an official journal of the American Association for Cancer Research, 16(24), 6132-6138 (2010).

58. Hassan R, Sharon E, Thomas A et al. Phase 1 study of the antimesothelin immunotoxin SS1P in combination with pemetrexed and cisplatin for front-line therapy of 
pleural mesothelioma and correlation of tumor response with serum mesothelin, megakaryocyte potentiating factor, and cancer antigen 125. Cancer, 120(21), 3311-3319 (2014).

59. Beatty GL, Haas AR, Maus MV et al. Mesothelin-specific Chimeric Antigen Receptor mRNA-Engineered T cells Induce Anti-Tumor Activity in Solid Malignancies. Cancer immunology research, 2(2), 112-120 (2014).

60. Blumenschein GR, Hassan R, Moore KN et al. Phase I study of anti-mesothelin antibody drug conjugate anetumab ravtansine (AR). In: 2016 ASCO Annual Meeting. (Ed.^(Eds) (Chicago, USA, 2016)

61. Schuberth PC, Hagedorn C, Jensen SM et al. Treatment of malignant pleural mesothelioma by fibroblast activation protein-specific re-directed T cells. Journal of Translational Medicine, 11, 187-187 (2013).

62. Ertl HC, Zaia J, Rosenberg SA et al. Considerations for the clinical application of chimeric antigen receptor T cells: observations from a recombinant DNA Advisory Committee Symposium held June 15, 2010. Cancer Res, 71(9), 3175-3181 (2011).

63. Tan A, Porcher R, Crequit P, Ravaud P, Dechartres A. Differences in Treatment Effect Size Between Overall Survival and Progression-Free Survival in Immunotherapy Trials: A Meta-Epidemiologic Study of Trials With Results Posted at ClinicalTrials.gov. $J$ Clin Oncol, Jco2016712109 (2017). 
Table 1: Examples of clinical trials relating to vaccine immunotherapy in mesothelioma. An asterisk $(*)$ indicates that the number of patients is the projected accrual, not the number actually enrolled.

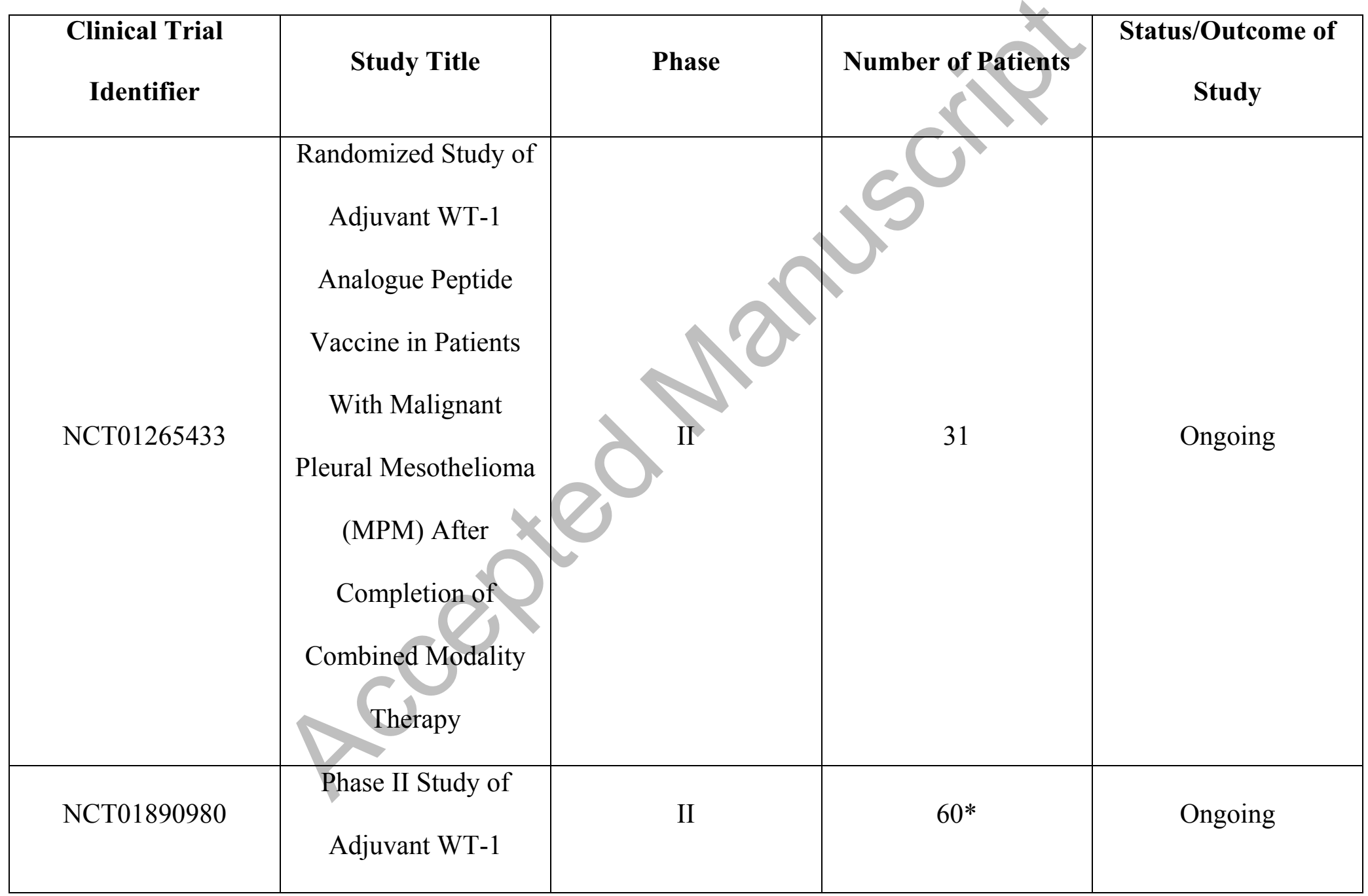




\begin{tabular}{|c|c|c|c|c|}
\hline & $\begin{array}{l}\text { Analogue Peptide } \\
\text { Vaccine in MPM } \\
\text { Patients After } \\
\text { MSK10-134 }\end{array}$ & & & \\
\hline NCT02649829 & $\begin{array}{l}\text { Autologous Dendritic } \\
\text { Cell Vaccination in } \\
\text { Mesothelioma } \\
\text { (MESODEC) }\end{array}$ & $\mathrm{I} / \mathrm{II}$ & $20^{*}$ & Recruiting \\
\hline NCT02408016 & $\begin{array}{l}\text { Genetically Modified } \\
\text { T Cells in Treating } \\
\text { Patients With Stage } \\
\text { III-IV Non-small Cell } \\
\text { Lung Cancer or } \\
\text { Mesothelioma }\end{array}$ & I/II & $20^{*}$ & Recruiting \\
\hline NCT01258868 & $\begin{array}{l}\text { Tumor Cell Vaccines } \\
\text { With ISCOMATRIX }\end{array}$ & I & 44 & Terminated \\
\hline
\end{tabular}




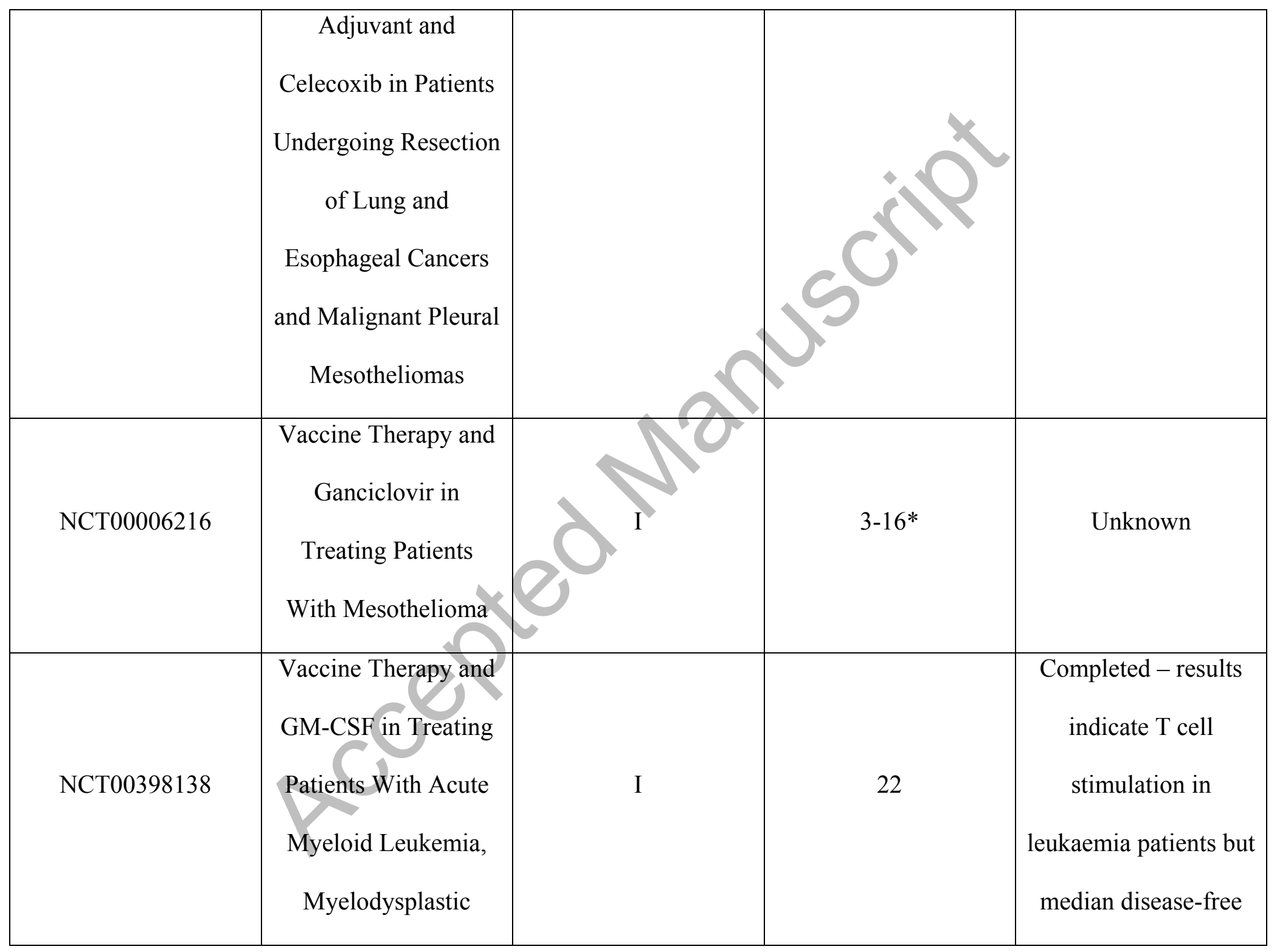




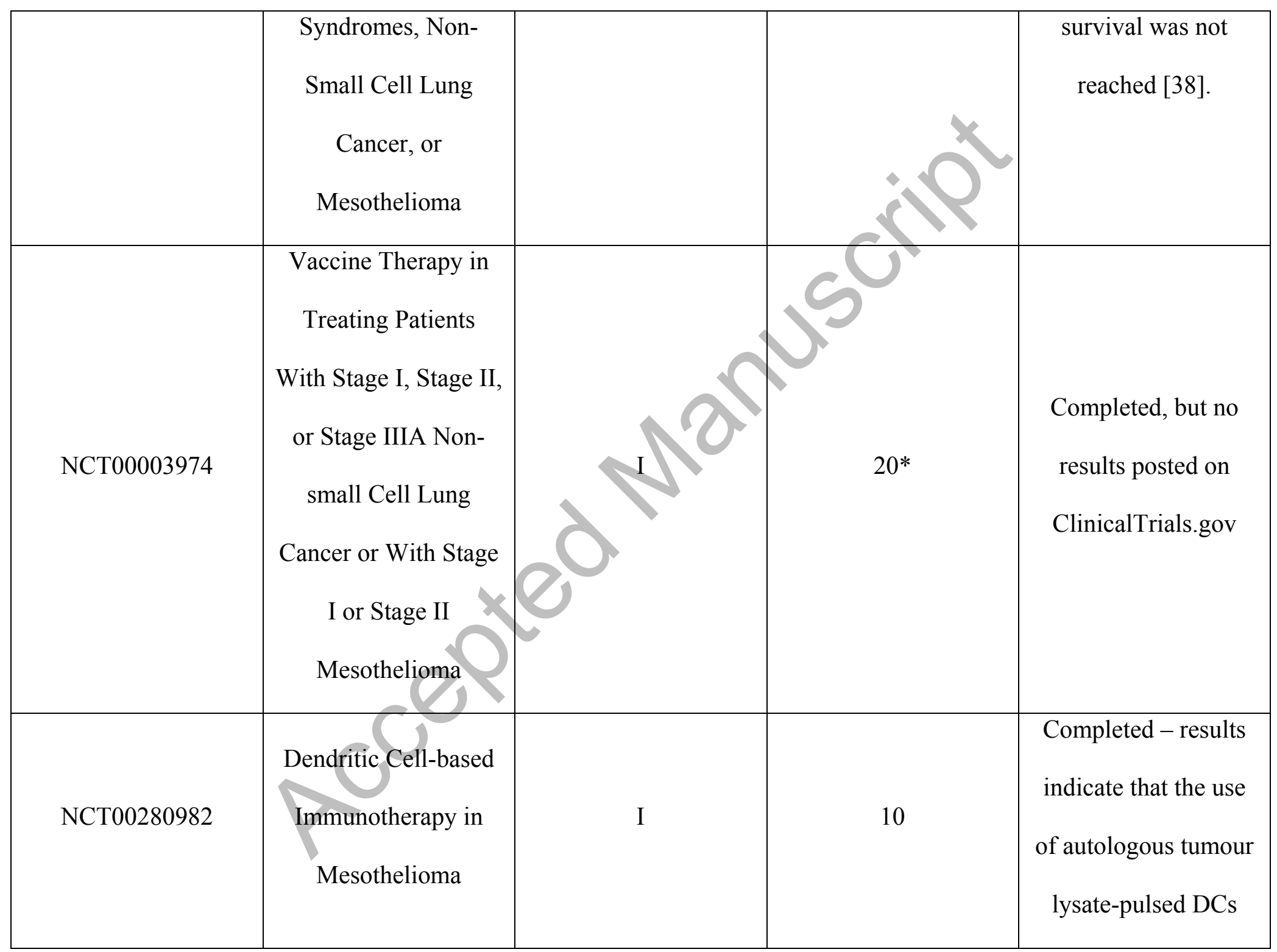




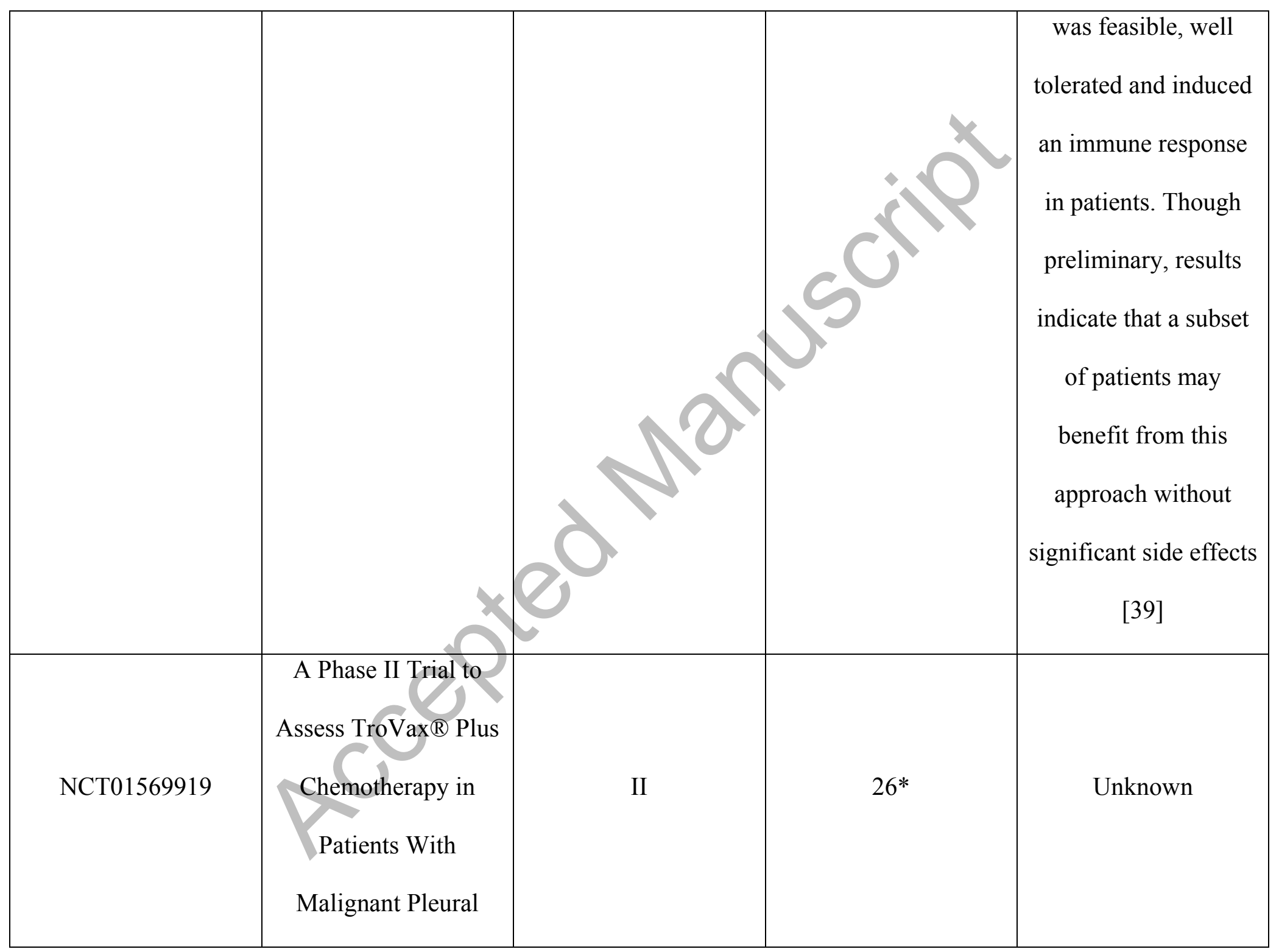




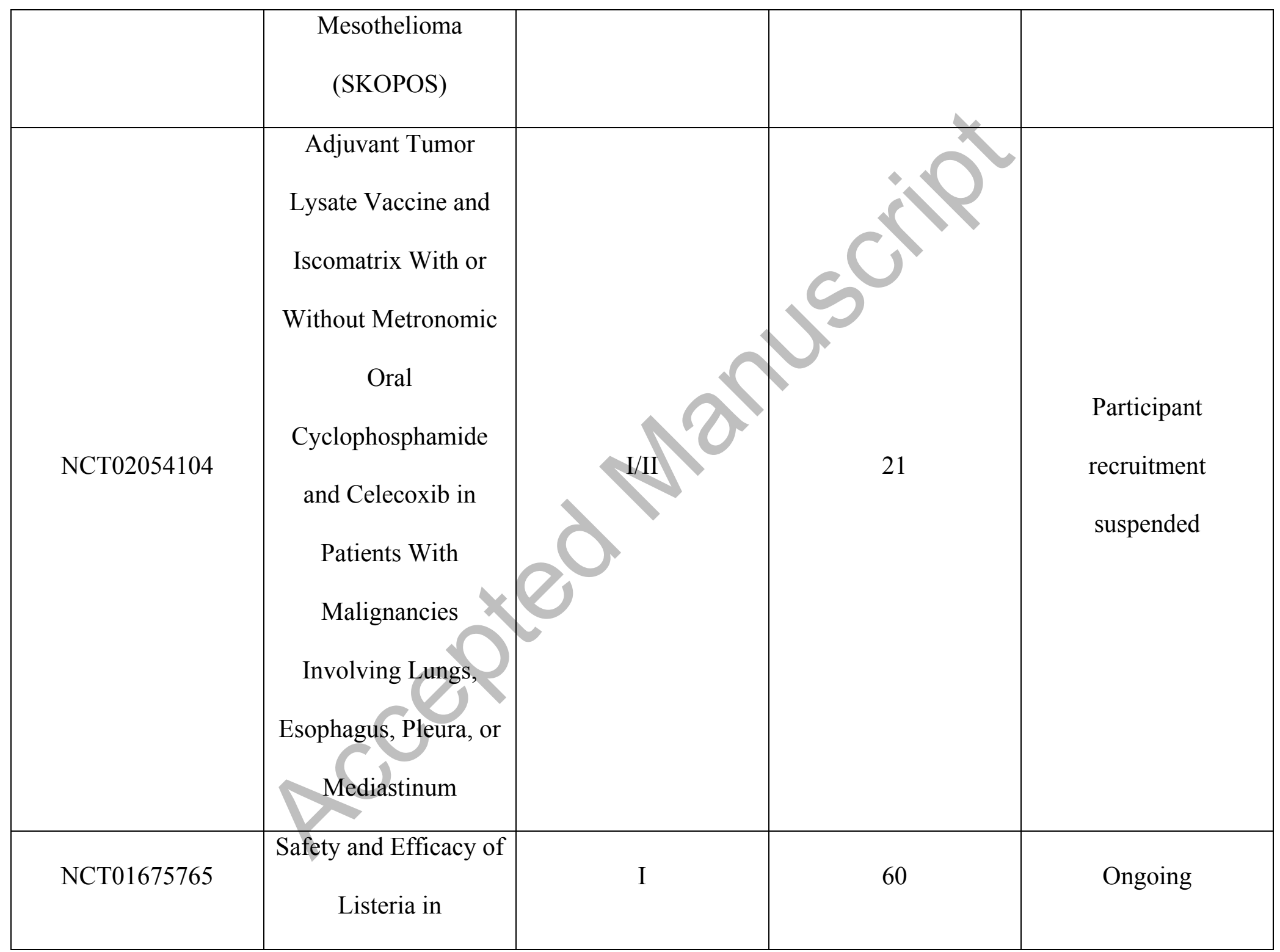




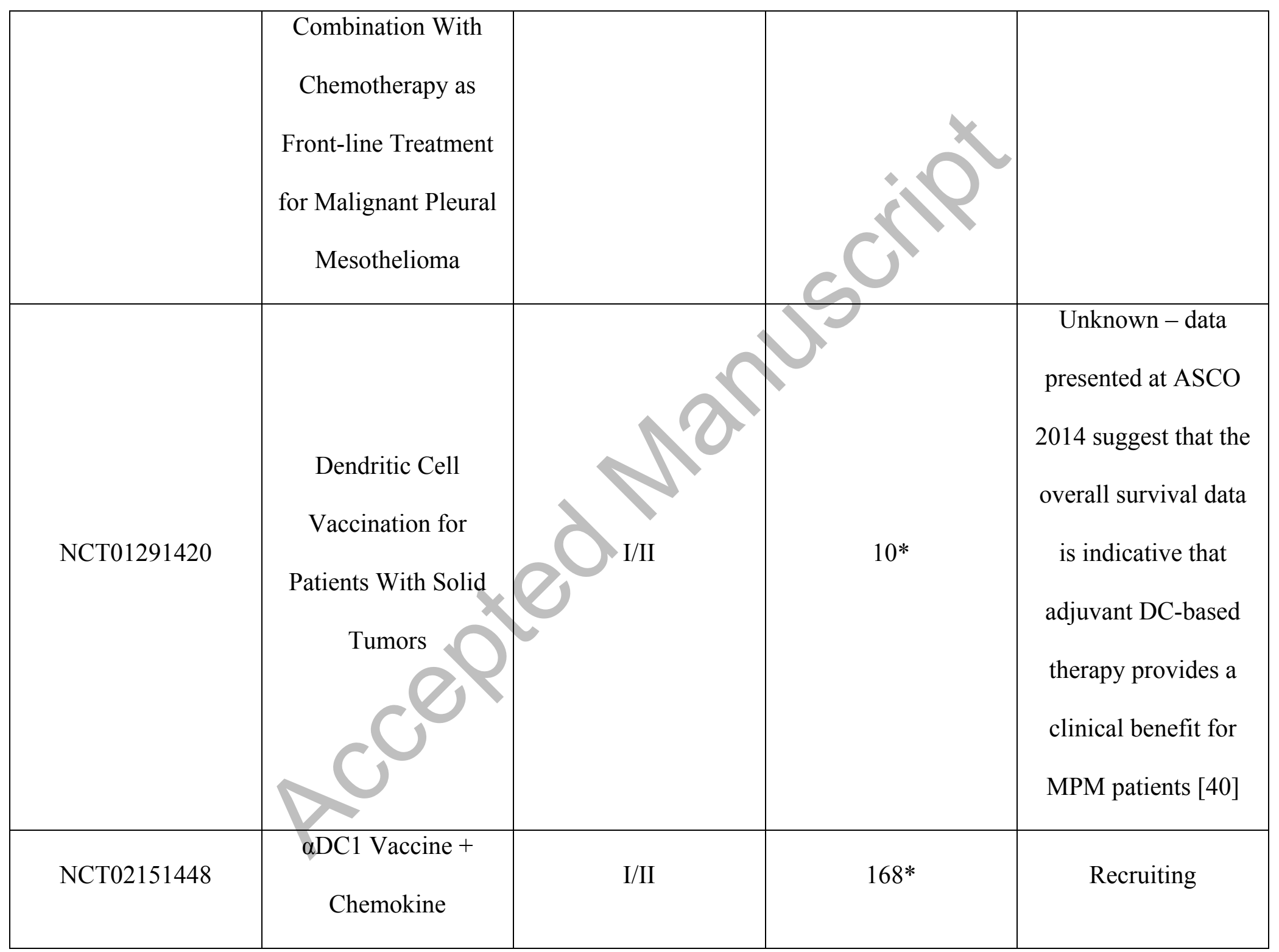




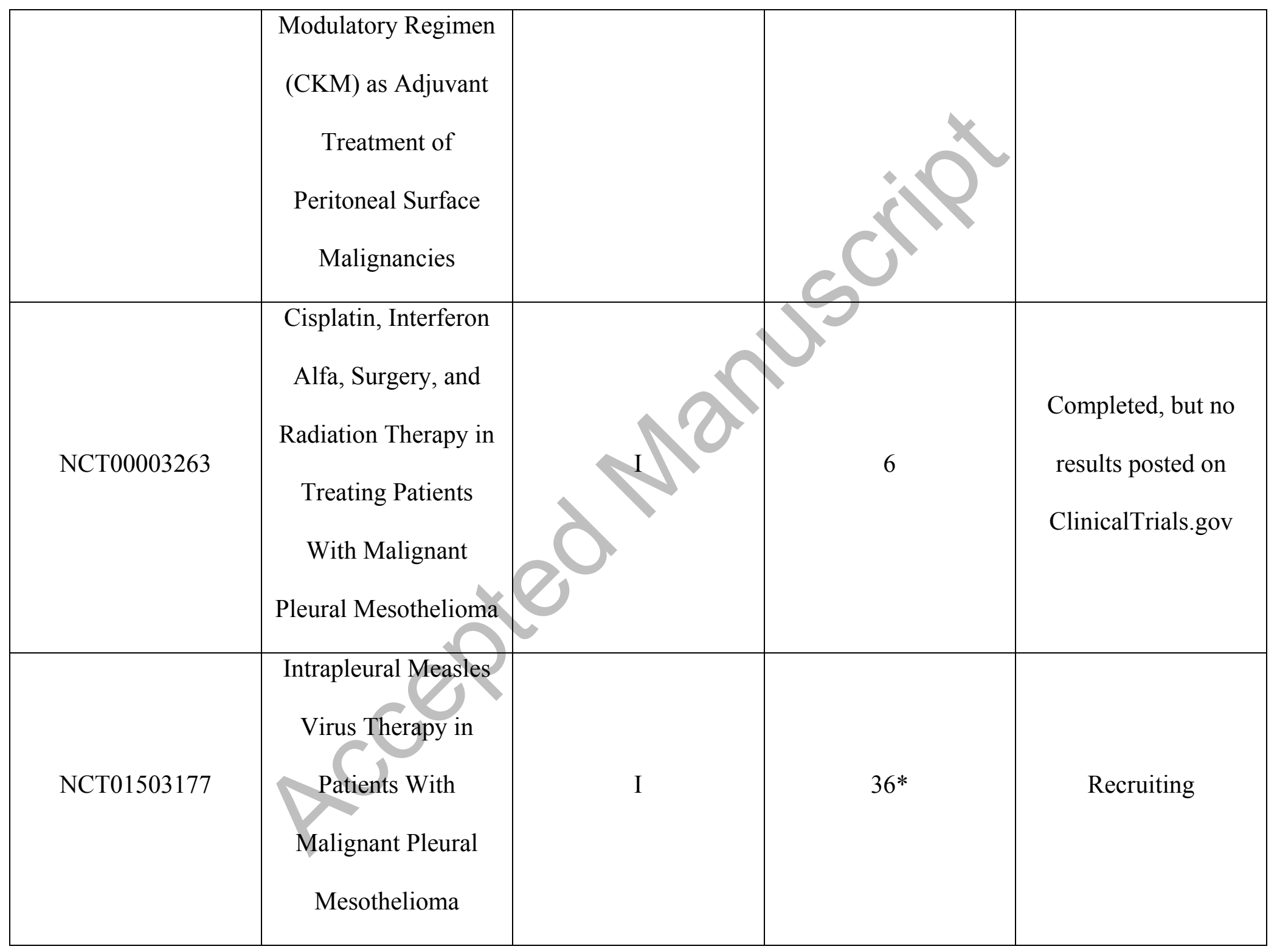




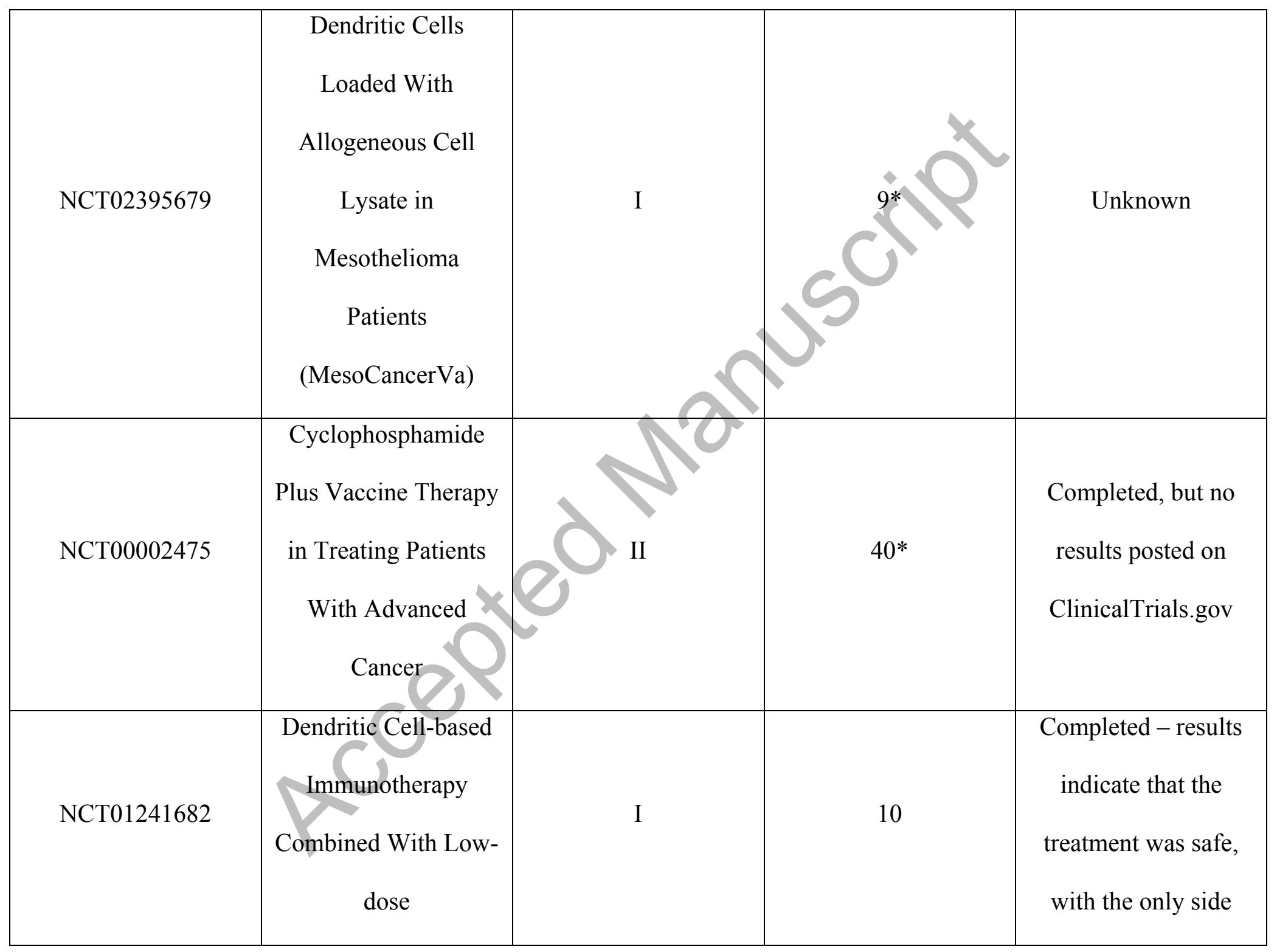




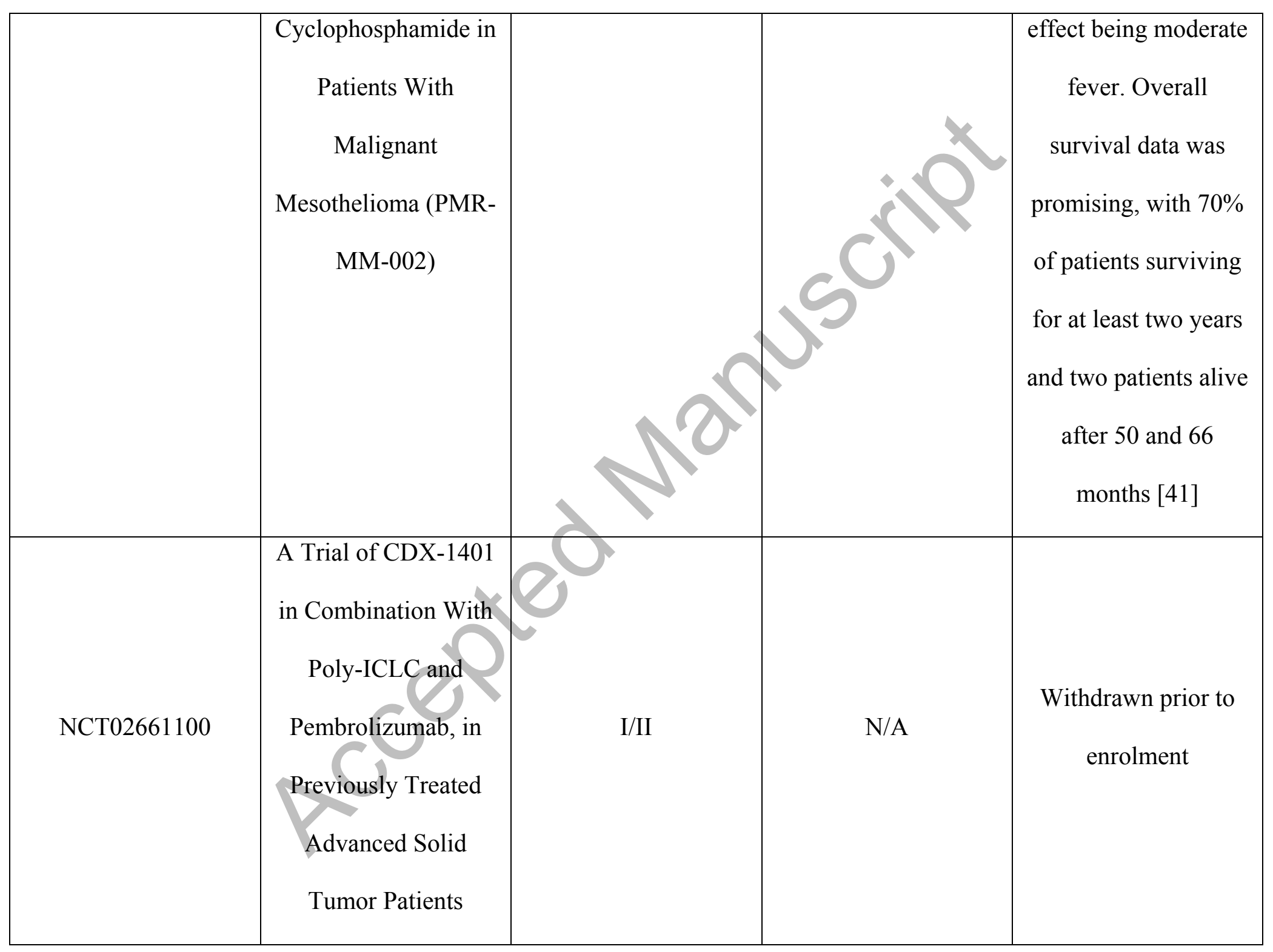




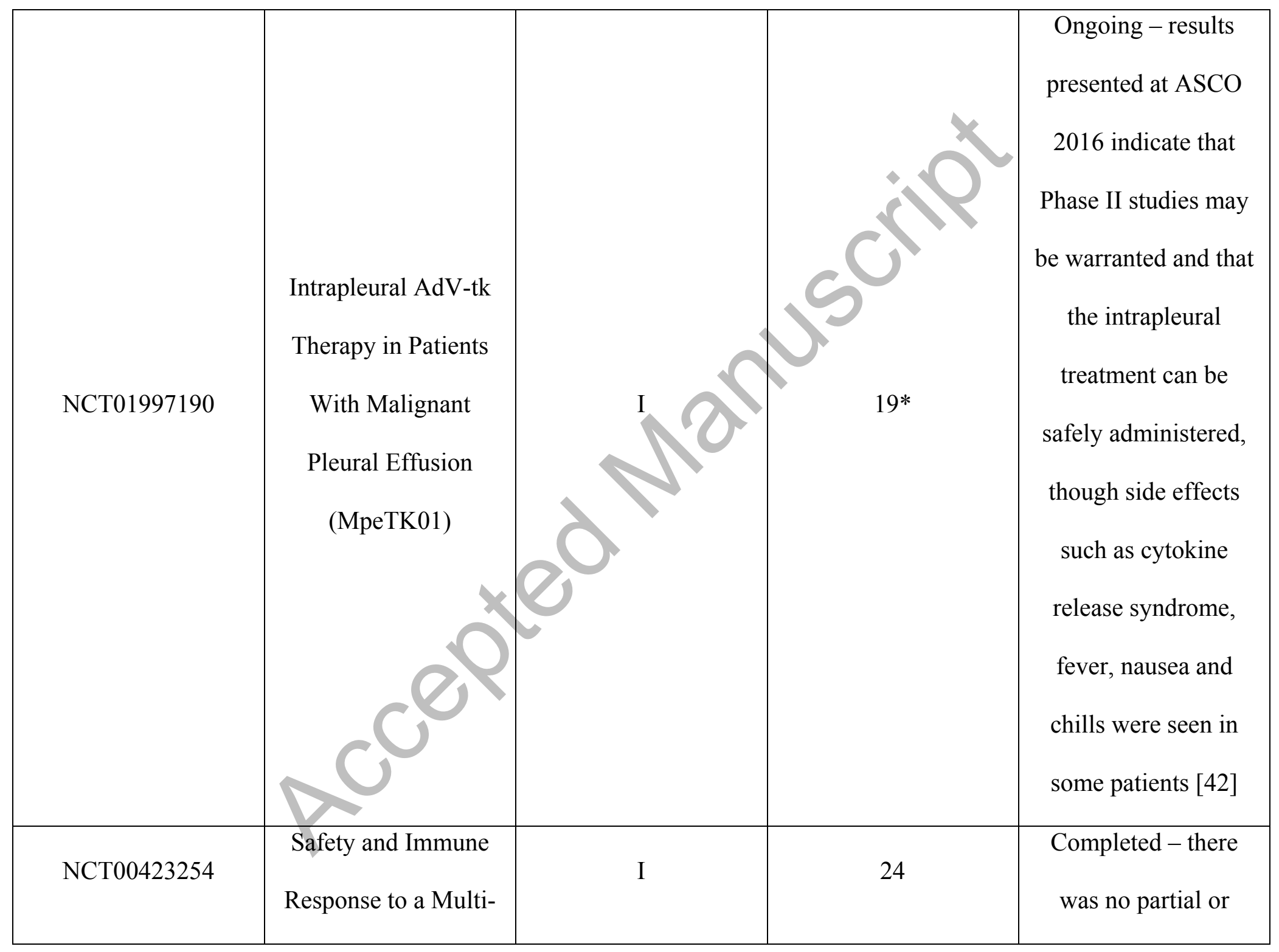




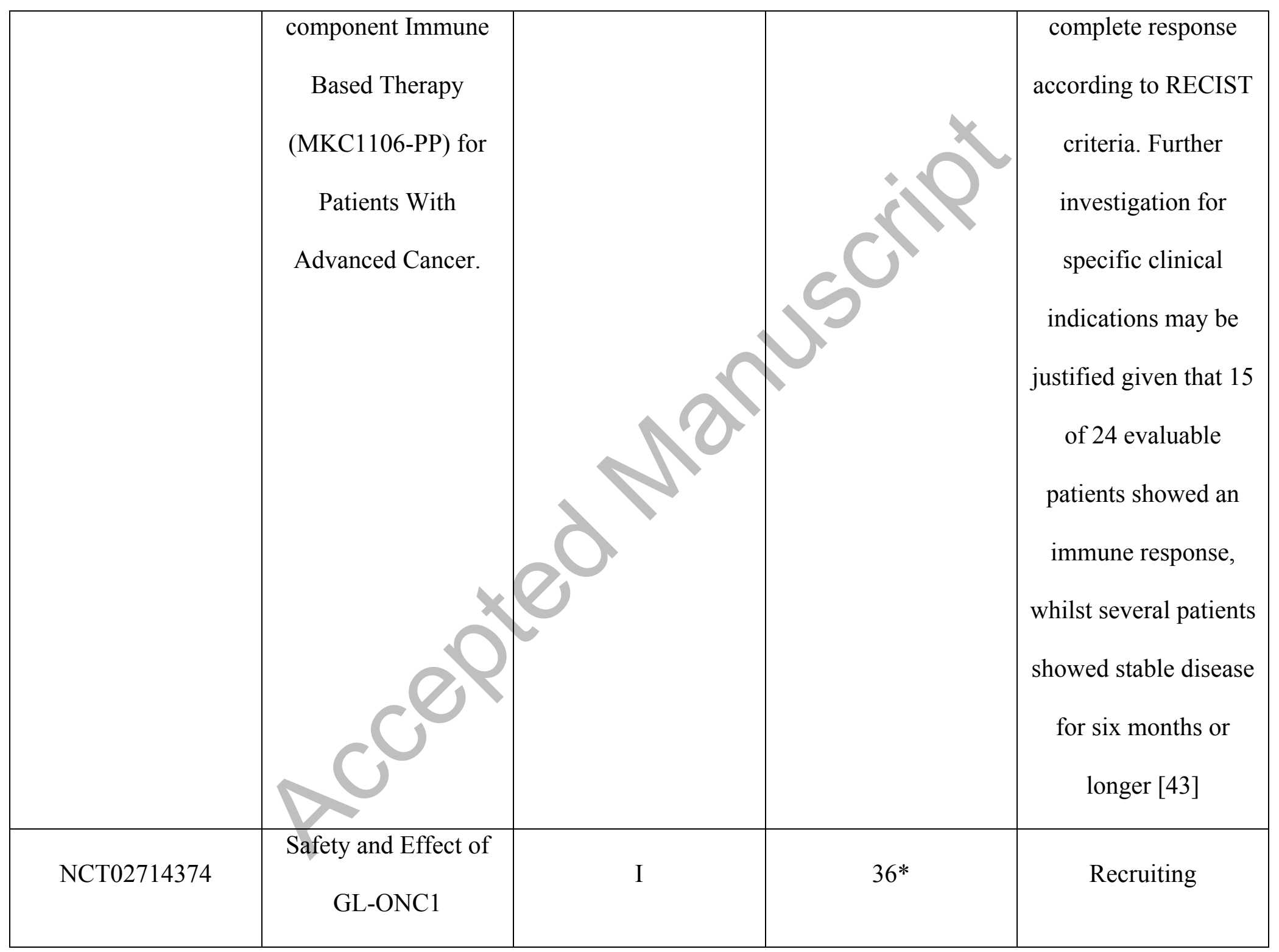




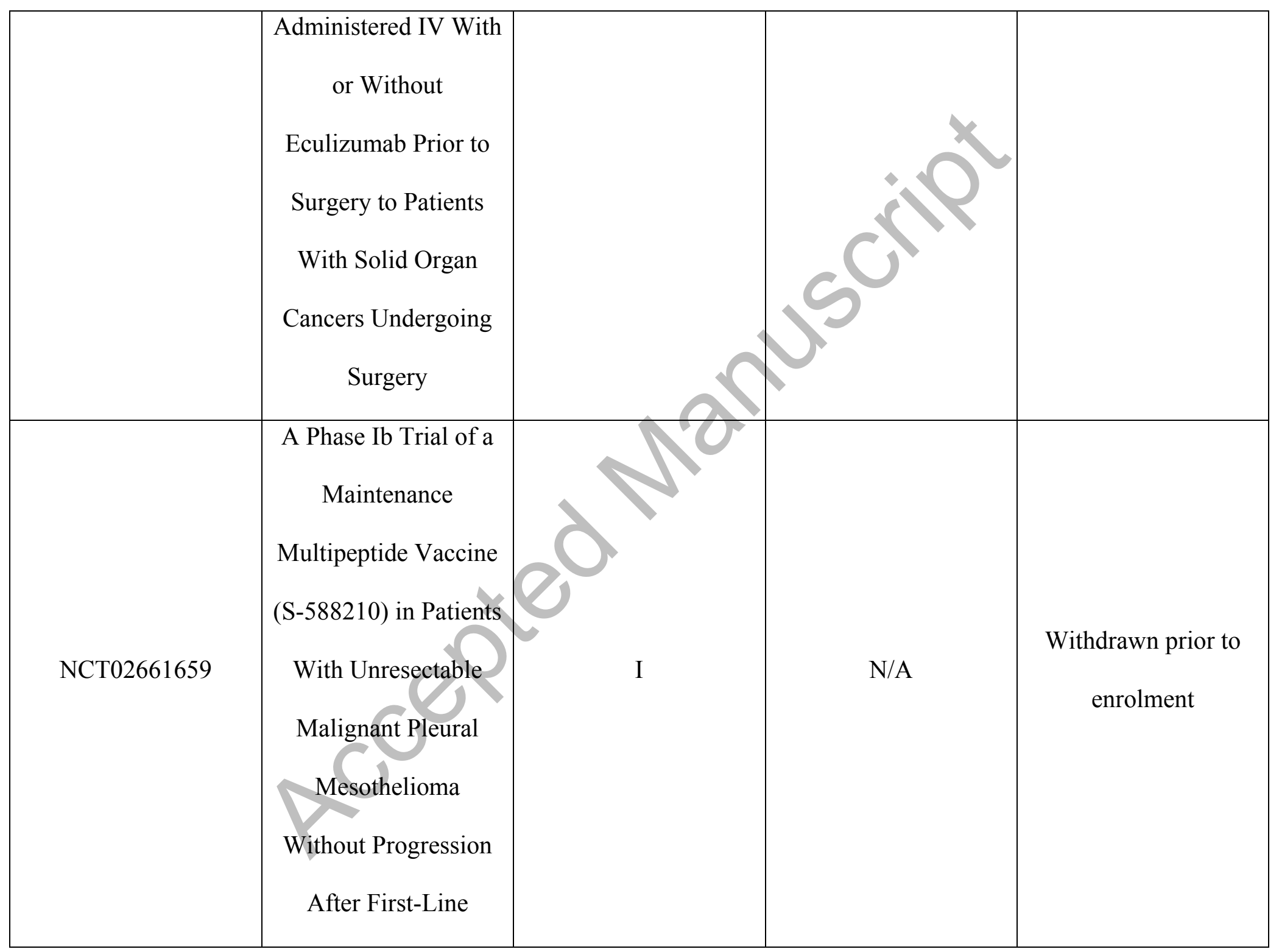




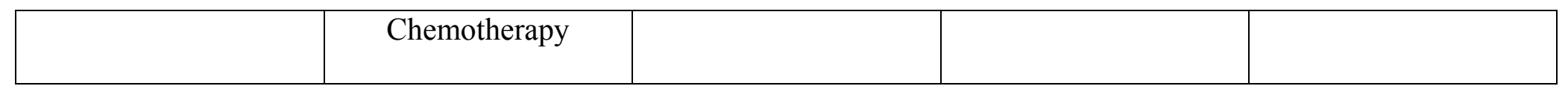

Table 2: Examples of clinical trials relating to immune checkpoint blockade in mesothelioma. An asterisk $(*)$ indicates that the number of patients is the projected accrual, not the number actually enrolled.

\begin{tabular}{|c|c|c|c|c|}
\hline $\begin{array}{c}\text { Clinical Trial } \\
\text { Identifier }\end{array}$ & Study Title & Phase & Number of Patients & $\begin{array}{c}\text { Status/Outcome of } \\
\text { Study }\end{array}$ \\
\hline NCT01843374 & $\begin{array}{c}\text { Randomized, Double- } \\
\text { blind Study } \\
\text { Comparing } \\
\text { Tremelimumab to } \\
\text { Placebo in Subjects } \\
\text { With Unresectable } \\
\text { Malignant } \\
\text { Mesothelioma } \\
\text { (Tremelimumab) }\end{array}$ & II & 658 & $\begin{array}{c}\text { Ongoing - } \\
\text { preliminary results } \\
\text { presented at ASCO } \\
\text { were detailed } \\
\text { previously, but in } \\
\text { brief } 81 \% \text { of patients } \\
\text { died and there was no } \\
\text { statistically } \\
\text { significant difference } \\
\text { in overall survival }\end{array}$ \\
\hline
\end{tabular}




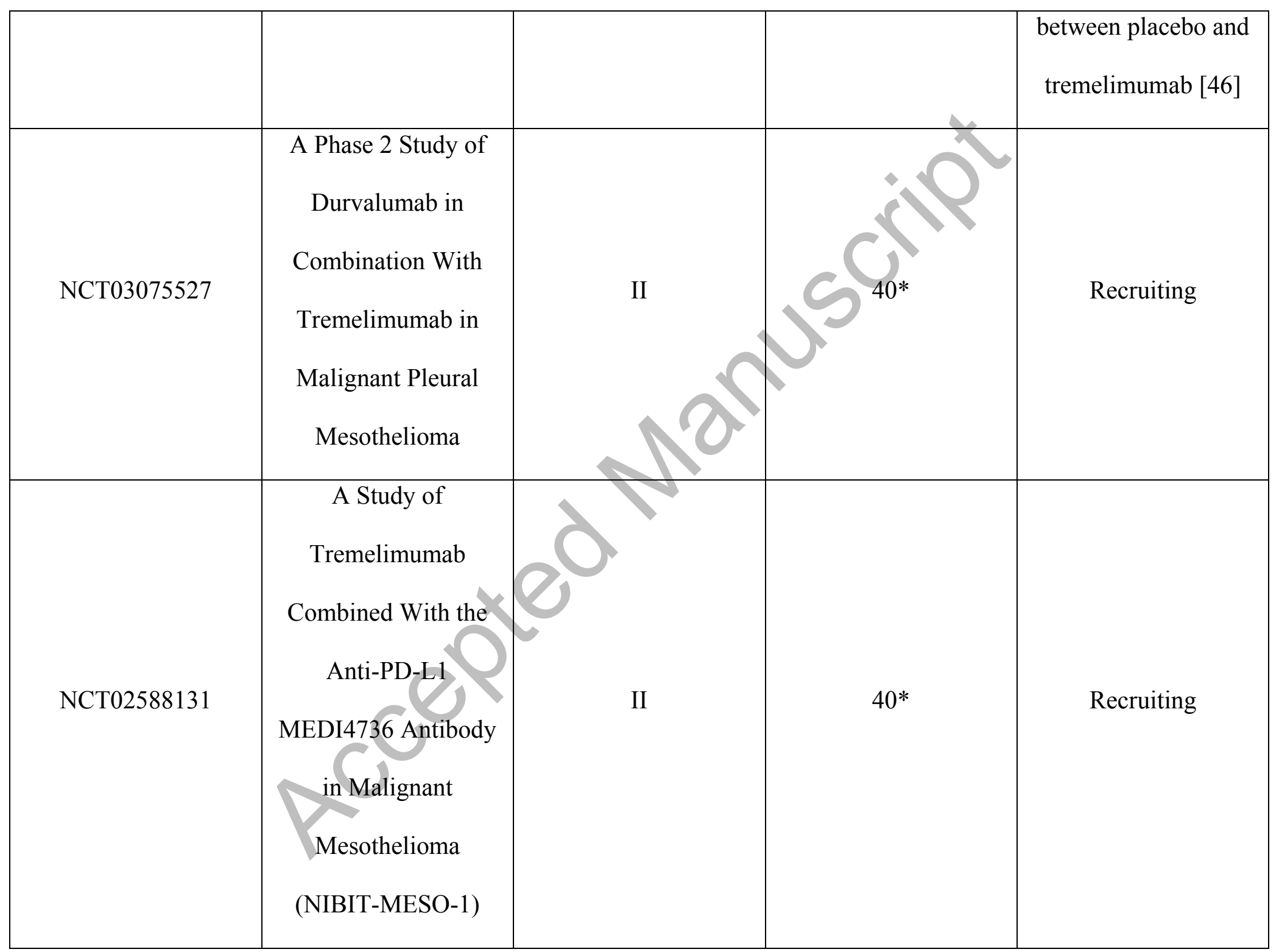




\begin{tabular}{|c|c|c|c|c|}
\hline NCT02592551 & $\begin{array}{c}\text { MEDI4736 Or } \\
\text { MEDI4736 + } \\
\text { Tremelimumab In } \\
\text { Surgically Resectable } \\
\text { Malignant Pleural } \\
\text { Mesothelioma }\end{array}$ & II & & Recruiting \\
\hline NCT02141347 & $\begin{array}{c}\text { Ph1 to Assess Safety, } \\
\text { Tolerability of } \\
\text { Tremelimumab/ } \\
\text { Tremelimumab+MED } \\
\text { I4736 in Japanese } \\
\text { Solid Malignancies/ } \\
\text { Mesothelioma }\end{array}$ & I & 73 & $\begin{array}{l}\text { Completed, but no } \\
\text { results posted on } \\
\text { ClinicalTrials.gov }\end{array}$ \\
\hline NCT01655888 & $\begin{array}{l}\text { The Anti-CTLA-4 } \\
\text { Monoclonal Antibody } \\
\text { Tremelimumab in }\end{array}$ & II & 29 & $\begin{array}{l}\text { Unknown - results } \\
\text { published in } 2015 \\
\text { indicate that one }\end{array}$ \\
\hline
\end{tabular}




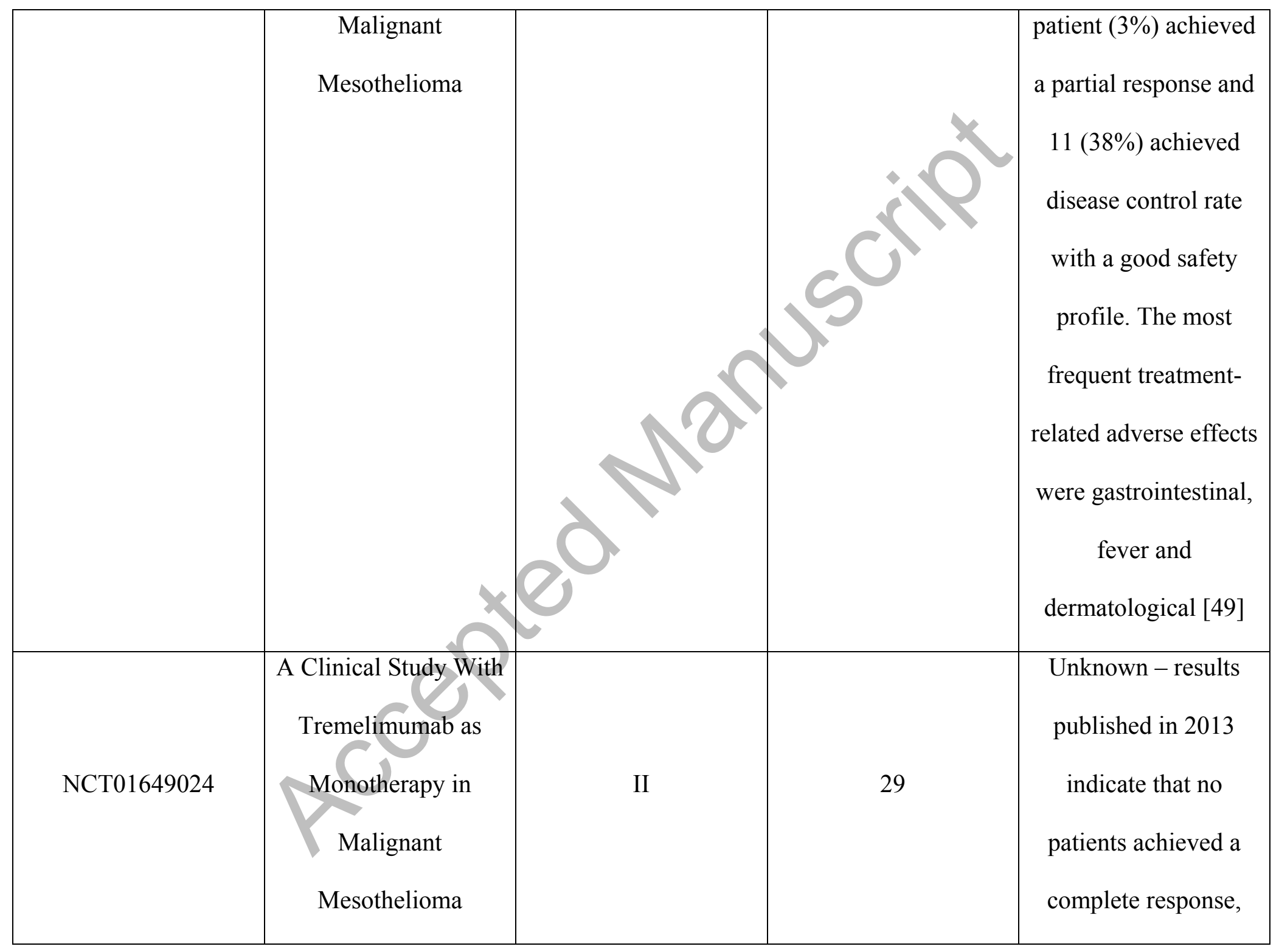




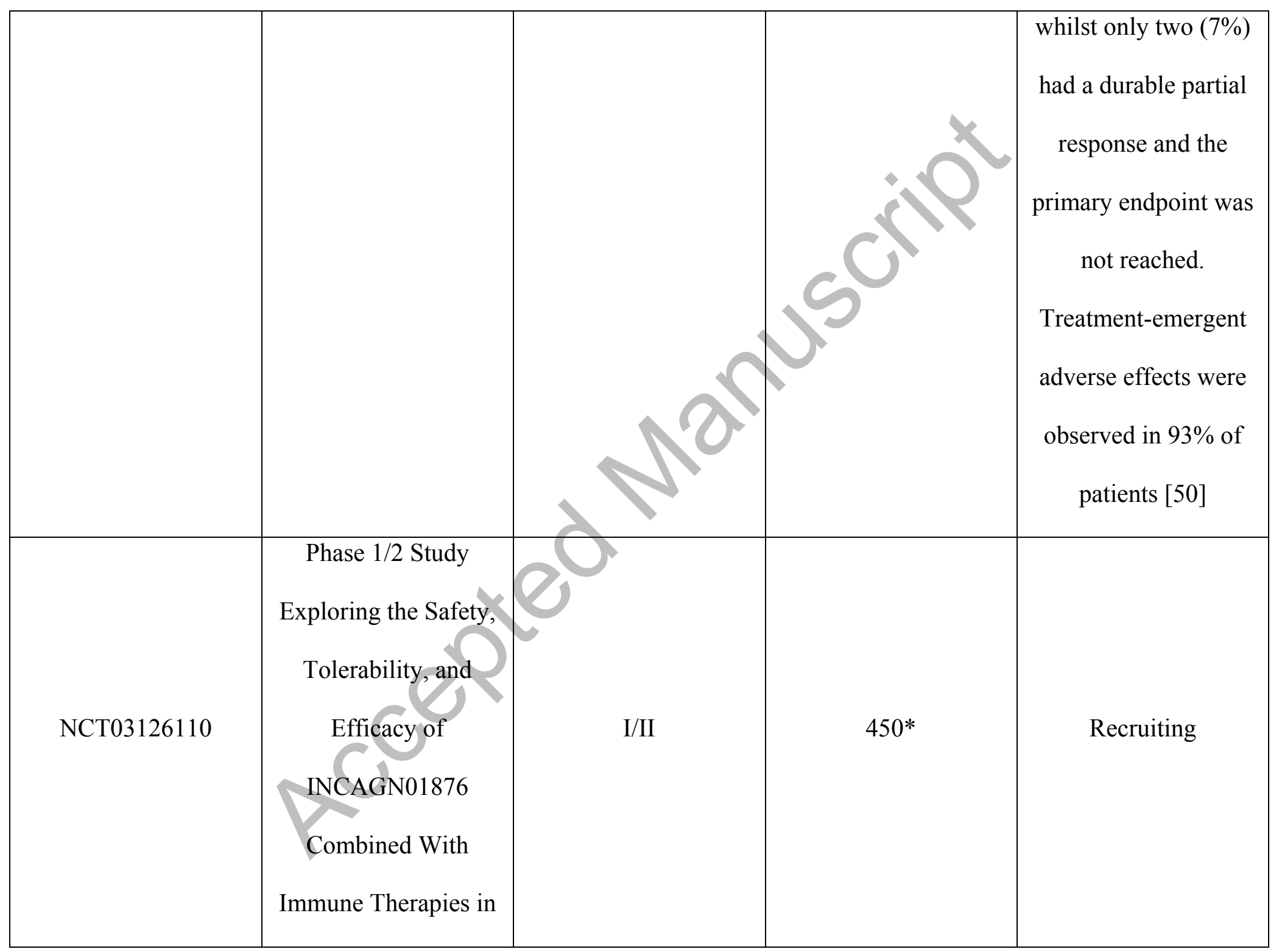




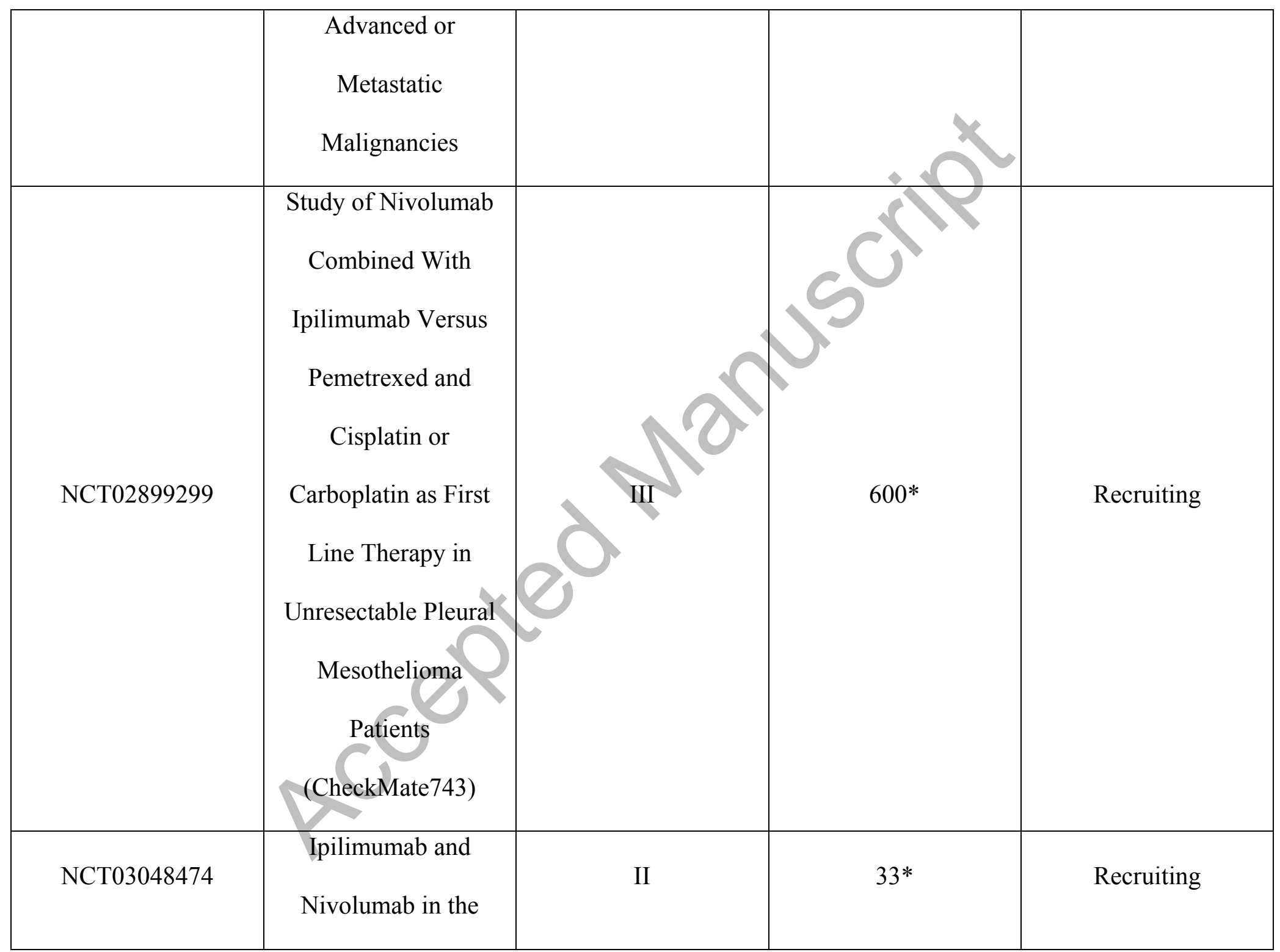




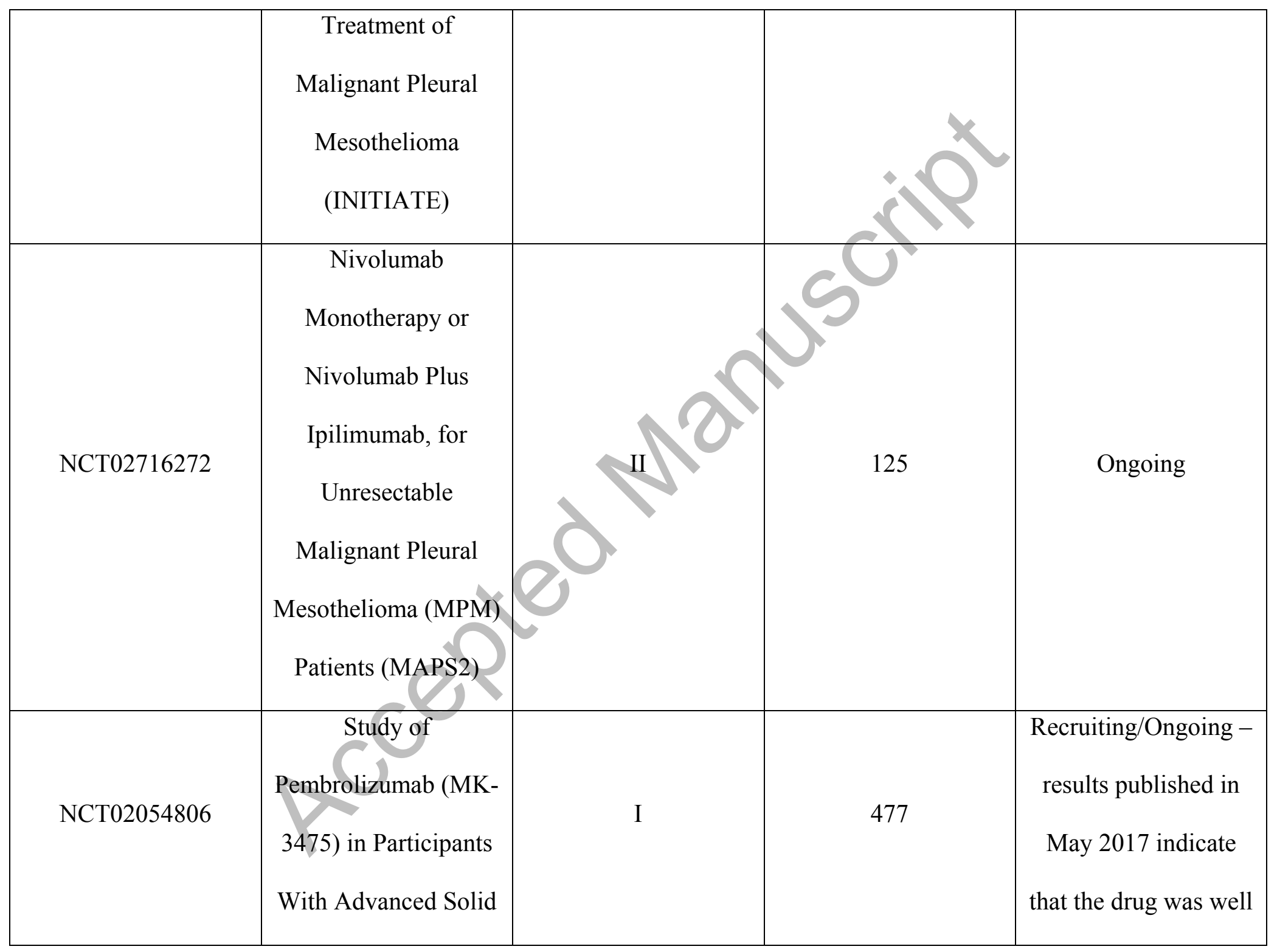




\begin{tabular}{|c|c|c|c|c|}
\hline & $\begin{array}{l}\text { Tumors (MK-3475- } \\
\text { 028/KEYNOTE-28) }\end{array}$ & & & $\begin{array}{l}\text { tolerated, might } \\
\text { confer an anti-tumour } \\
\text { effect and that further } \\
\text { investigations were } \\
\text { warranted [48] }\end{array}$ \\
\hline NCT02707666 & $\begin{array}{l}\text { A Pilot Window-Of- } \\
\text { Opportunity Study of } \\
\text { the Anti-PD-1 } \\
\text { Antibody } \\
\text { Pembrolizumab in } \\
\text { Patients With } \\
\text { Resectable Malignant } \\
\text { Pleural Mesothelioma }\end{array}$ & & $15^{*}$ & Recruiting \\
\hline NCT02991482 & $\begin{array}{l}\text { PembROlizuMab } \\
\text { Immunotherapy } \\
\text { Versus Standard }\end{array}$ & III & $142 *$ & Not yet recruiting \\
\hline
\end{tabular}




\begin{tabular}{|c|c|c|c|c|}
\hline & $\begin{array}{l}\text { Chemotherapy for } \\
\text { Advanced prE-treated } \\
\text { Malignant Pleural } \\
\text { Mesothelioma } \\
\text { (PROMISE-meso) }\end{array}$ & & & \\
\hline NCT02784171 & $\begin{array}{c}\text { Pembrolizumab in } \\
\text { Patients With } \\
\text { Advanced Malignant } \\
\text { Pleural Mesothelioma }\end{array}$ & & $126^{*}$ & Recruiting \\
\hline NCT02959463 & $\begin{array}{c}\text { Adjuvant } \\
\text { Pembrolizumab After } \\
\text { Radiation Therapy for } \\
\text { Lung-Intact } \\
\text { Malignant Pleural } \\
\text { Mesothelioma }\end{array}$ & I & $24^{*}$ & Recruiting \\
\hline NCT03126630 & Pembrolizumab With & $\mathrm{I} / \mathrm{II}$ & $134 *$ & Recruiting \\
\hline
\end{tabular}




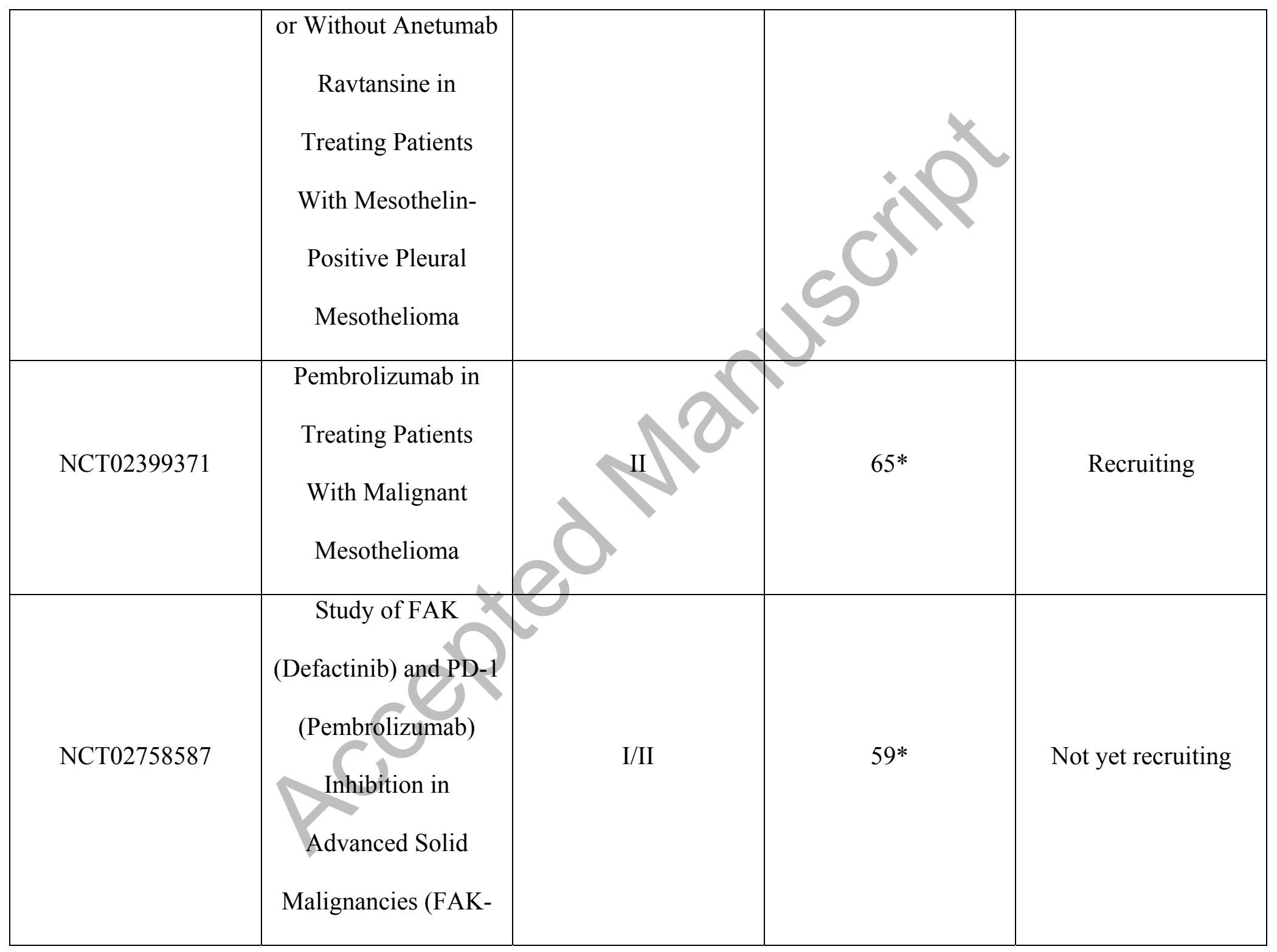




\begin{tabular}{|c|c|c|c|c|}
\hline & PD1) & & & \\
\hline NCT02661100 & $\begin{array}{l}\text { A Trial of CDX-1401 } \\
\text { in Combination With } \\
\text { Poly-ICLC and } \\
\text { Pembrolizumab, in } \\
\text { Previously Treated } \\
\text { Advanced Solid } \\
\text { Tumor Patients }\end{array}$ & $\mathrm{I} / \mathrm{II}$ & & $\begin{array}{c}\text { Withdrawn prior to } \\
\text { enrolment }\end{array}$ \\
\hline NCT02628067 & $\begin{array}{c}\text { Study of } \\
\text { Pembrolizumab (MK- } \\
\text { 3475) in Participants } \\
\text { With Advanced Solid } \\
\text { Tumors (MK-3475- } \\
\text { 158/KEYNOTE-158) }\end{array}$ & II & $1100 *$ & Recruiting \\
\hline NCT02856425 & $\begin{array}{c}\text { Trial Of } \\
\text { Pembrolizumab And }\end{array}$ & I & $18^{*}$ & Recruiting \\
\hline
\end{tabular}




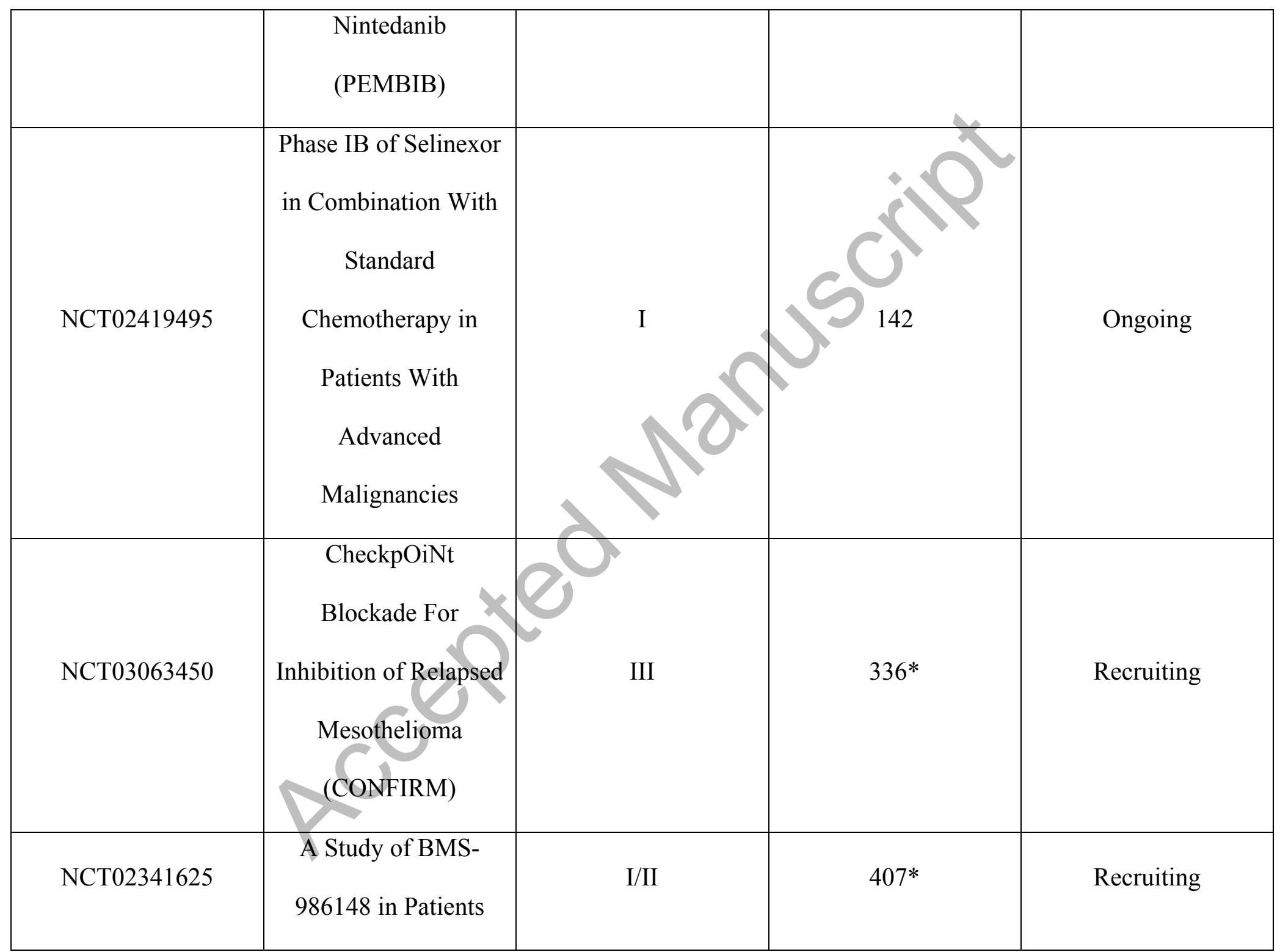




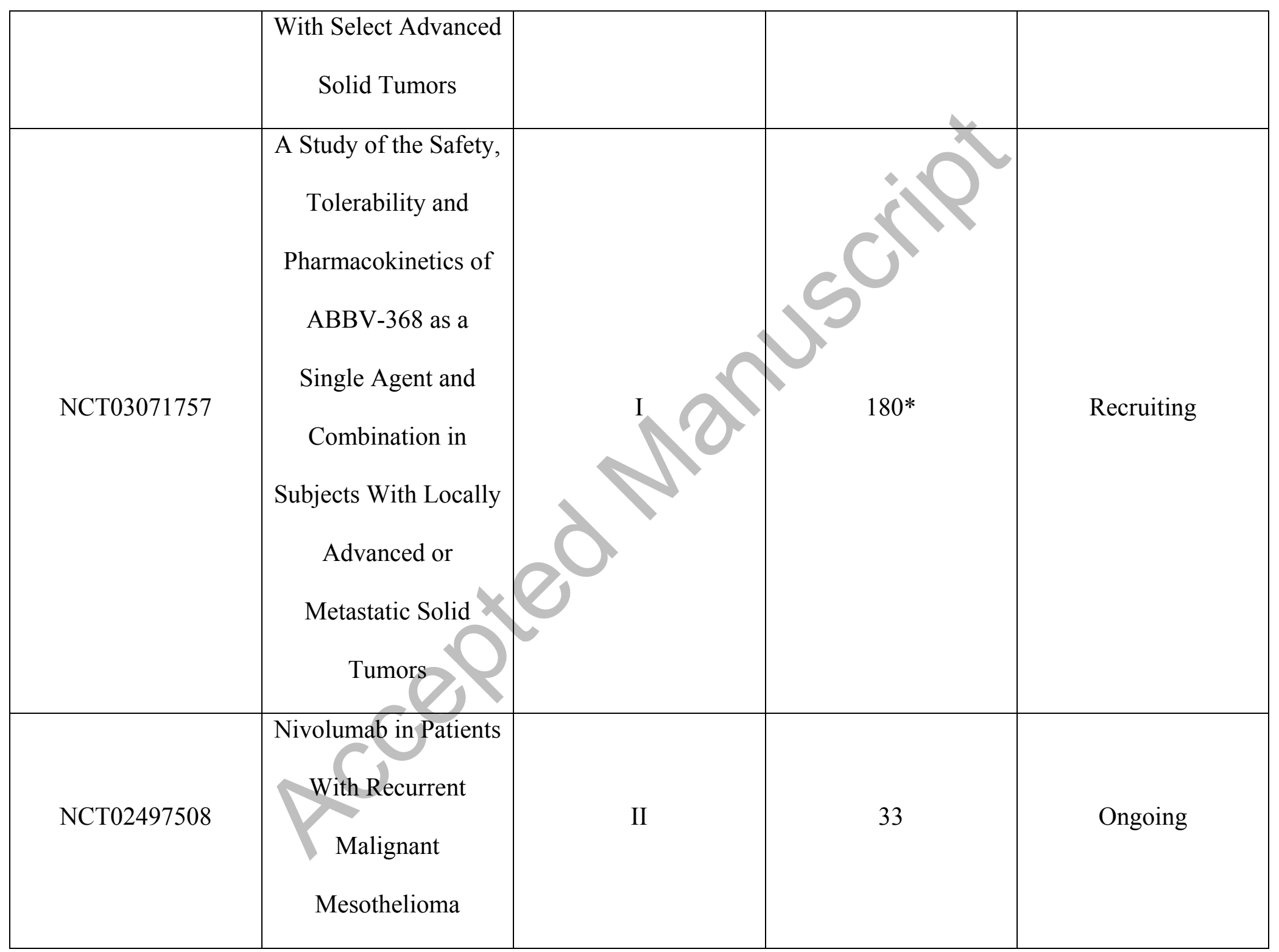




\begin{tabular}{|c|c|c|c|c|}
\hline & (NivoMes) & & & \\
\hline NCT02458638 & $\begin{array}{c}\text { A Study of } \\
\text { Atezolizumab in } \\
\text { Advanced Solid } \\
\text { Tumors }\end{array}$ & II & & Recruiting \\
\hline NCT03074513 & $\begin{array}{c}\text { Atezolizumab and } \\
\text { Bevacizumab in Rare } \\
\text { Solid Tumors }\end{array}$ & II & $160 *$ & Recruiting \\
\hline NCT01772004 & $\begin{array}{c}\text { Avelumab in } \\
\text { Metastatic or Locally } \\
\text { Advanced Solid } \\
\text { Tumors (JAVELIN } \\
\text { Solid Tumor) }\end{array}$ & I & $1706^{*}$ & $\begin{array}{c}\text { Recruiting - } \\
\text { preliminary safety } \\
\text { data indicates an } \\
\text { acceptable safety } \\
\text { profile in pre-treated } \\
\text { populations [51] }\end{array}$ \\
\hline
\end{tabular}


Table 3: Examples of clinical trials relating to the use of monoclonal antibodies in mesothelioma. An asterisk $(*)$ indicates that the number of patients is the projected accrual, not the number actually enrolled.

\begin{tabular}{|c|c|c|c|c|}
\hline $\begin{array}{c}\text { Clinical Trial } \\
\text { Identifier }\end{array}$ & Study Title & Phase & Number of Patients & $\begin{array}{c}\text { Status/Outcome of } \\
\text { Study }\end{array}$ \\
\hline NCT00325494 & $\begin{array}{l}\text { A Study of MORAb- } \\
009 \text { in Subjects With } \\
\text { Pancreatic Cancer, } \\
\text { Mesothelioma, or } \\
\text { Certain Types of } \\
\text { Ovarian or Lung } \\
\text { Cancer }\end{array}$ & & 24 & $\begin{array}{l}\text { Completed - results } \\
\text { indicate that MORAb- } \\
009 \text { (also known as } \\
\text { amatuximab) was } \\
\text { well tolerated and that } \\
\text { of the } 24 \text { patients, } 11 \\
\text { had stable disease } \\
\text { [57] }\end{array}$ \\
\hline NCT00738582 & $\begin{array}{l}\text { An Efficacy Study of } \\
\text { MORAb-009 } \\
\text { (Amatuximab) in } \\
\text { Subjects With Pleural }\end{array}$ & II & 89 & $\begin{array}{l}\text { Completed, but no } \\
\text { results posted on } \\
\text { ClinicalTrials.gov }\end{array}$ \\
\hline
\end{tabular}




\begin{tabular}{|c|c|c|c|c|}
\hline & $\begin{array}{l}\text { Mesothelioma } \\
\text { (Amatuximab) }\end{array}$ & & & \\
\hline NCT01413451 & $\begin{array}{l}\text { Amatuximab for High } \\
\text { Mesothelin Cancers }\end{array}$ & I & & Terminated \\
\hline NCT01521325 & $\begin{array}{l}\text { A Single-Dose Pilot } \\
\text { Study of Radiolabeled } \\
\text { Amatuximab } \\
\text { (MORAb-009) in } \\
\text { Mesothelin Over } \\
\text { Expressing Cancers }\end{array}$ & & 6 & $\begin{array}{l}\text { Completed, but no } \\
\text { results posted on } \\
\text { ClinicalTrials.gov }\end{array}$ \\
\hline NCT02357147 & $\begin{array}{l}\text { Study of the Safety } \\
\text { and Efficacy of } \\
\text { Amatuximab in } \\
\text { Combination With } \\
\text { Pemetrexed and } \\
\text { Cisplatin in Subjects }\end{array}$ & II & 108 & Ongoing \\
\hline
\end{tabular}




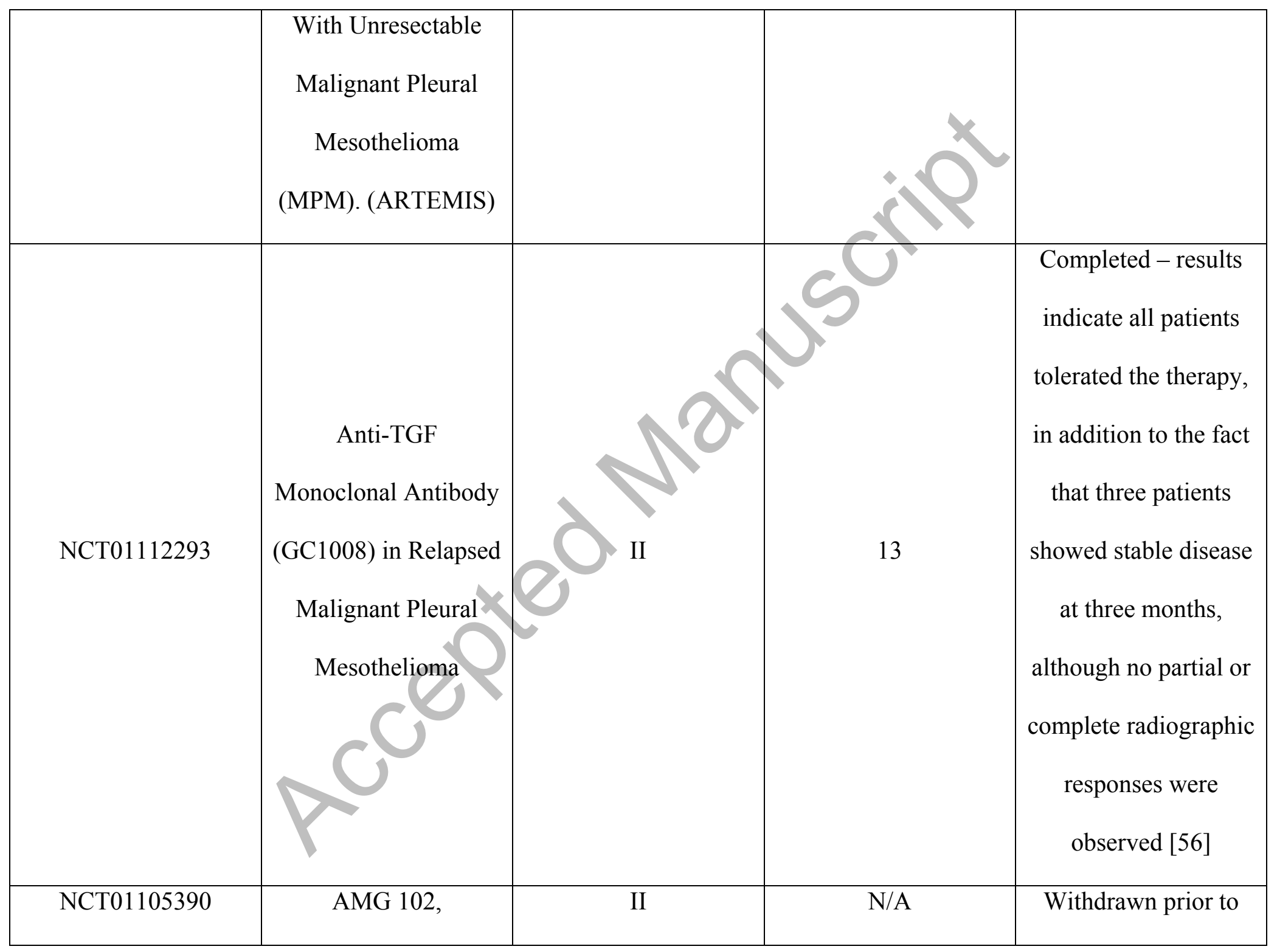




\begin{tabular}{|c|c|c|c|c|}
\hline & $\begin{array}{c}\text { Pemetrexed } \\
\text { Disodium, and } \\
\text { Cisplatin in Treating } \\
\text { Patients With } \\
\text { Malignant Pleural } \\
\text { Mesothelioma }\end{array}$ & & & enrolment \\
\hline NCT01160458 & $\begin{array}{l}\text { Phase II Study of } \\
\text { IMC-A12 in Patients } \\
\text { With Mesothelioma } \\
\text { Who Have Been } \\
\text { Previously Treated } \\
\text { With Chemotherapy }\end{array}$ & & 20 & Ongoing \\
\hline NCT01445392 & $\begin{array}{l}\text { SS1(dsFV)PE38 Plus } \\
\text { Pemetrexed and } \\
\text { Cisplatin to Treat } \\
\text { Malignant Pleural }\end{array}$ & I & 24 & $\begin{array}{l}\text { Completed - results } \\
\text { indicate that SS1P } \\
\text { when given with } \\
\text { pemetrexed and }\end{array}$ \\
\hline
\end{tabular}




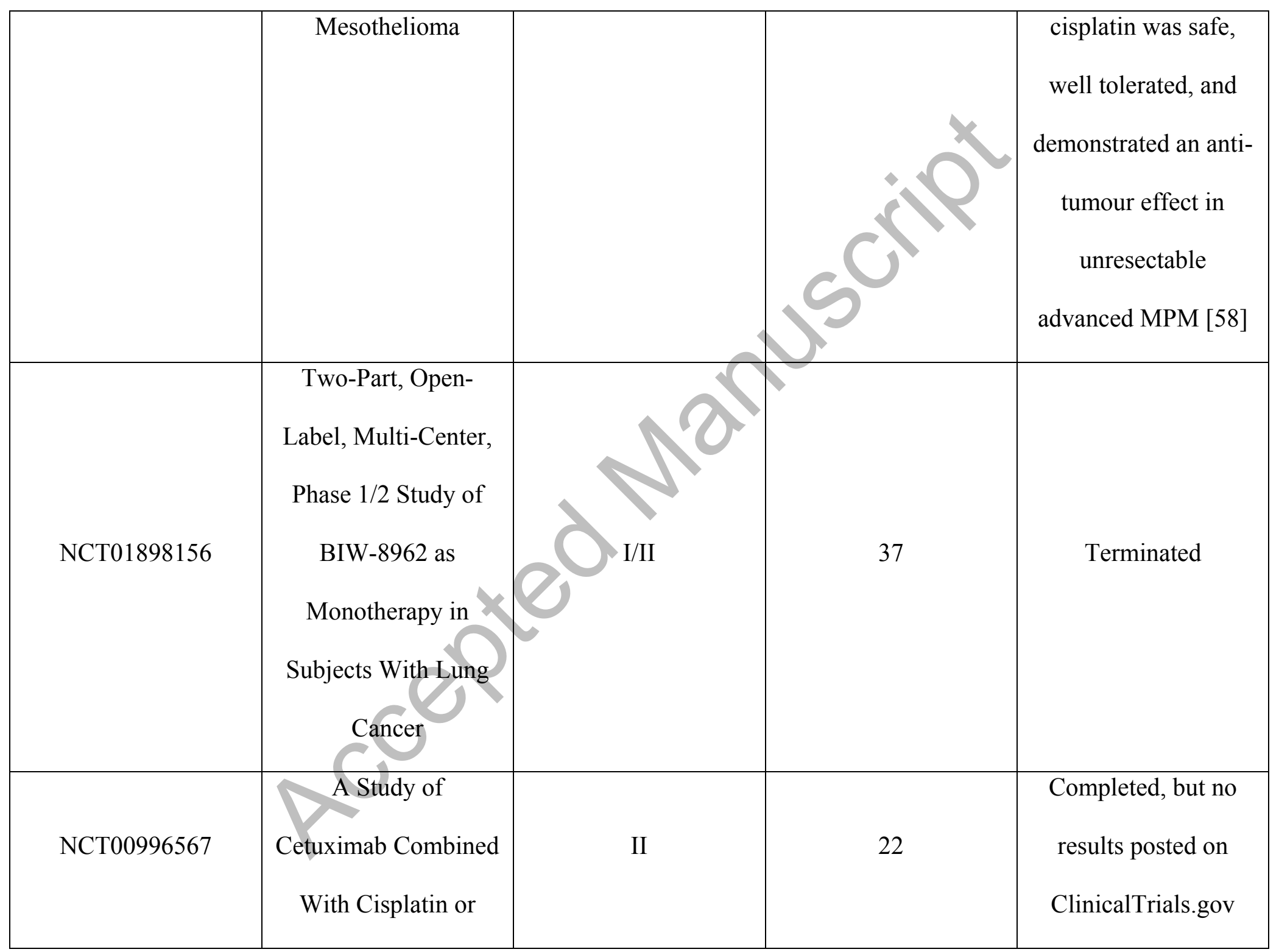




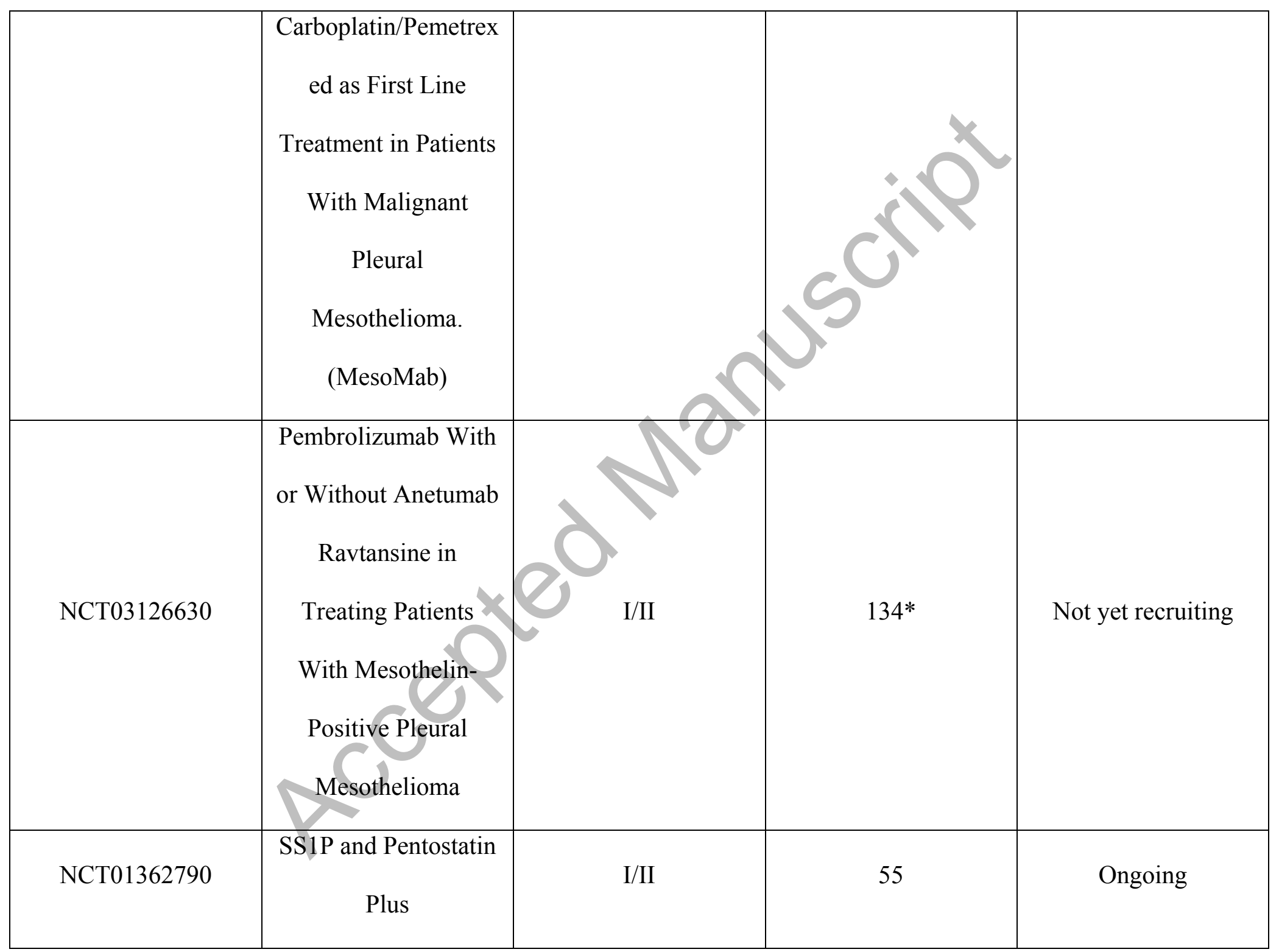




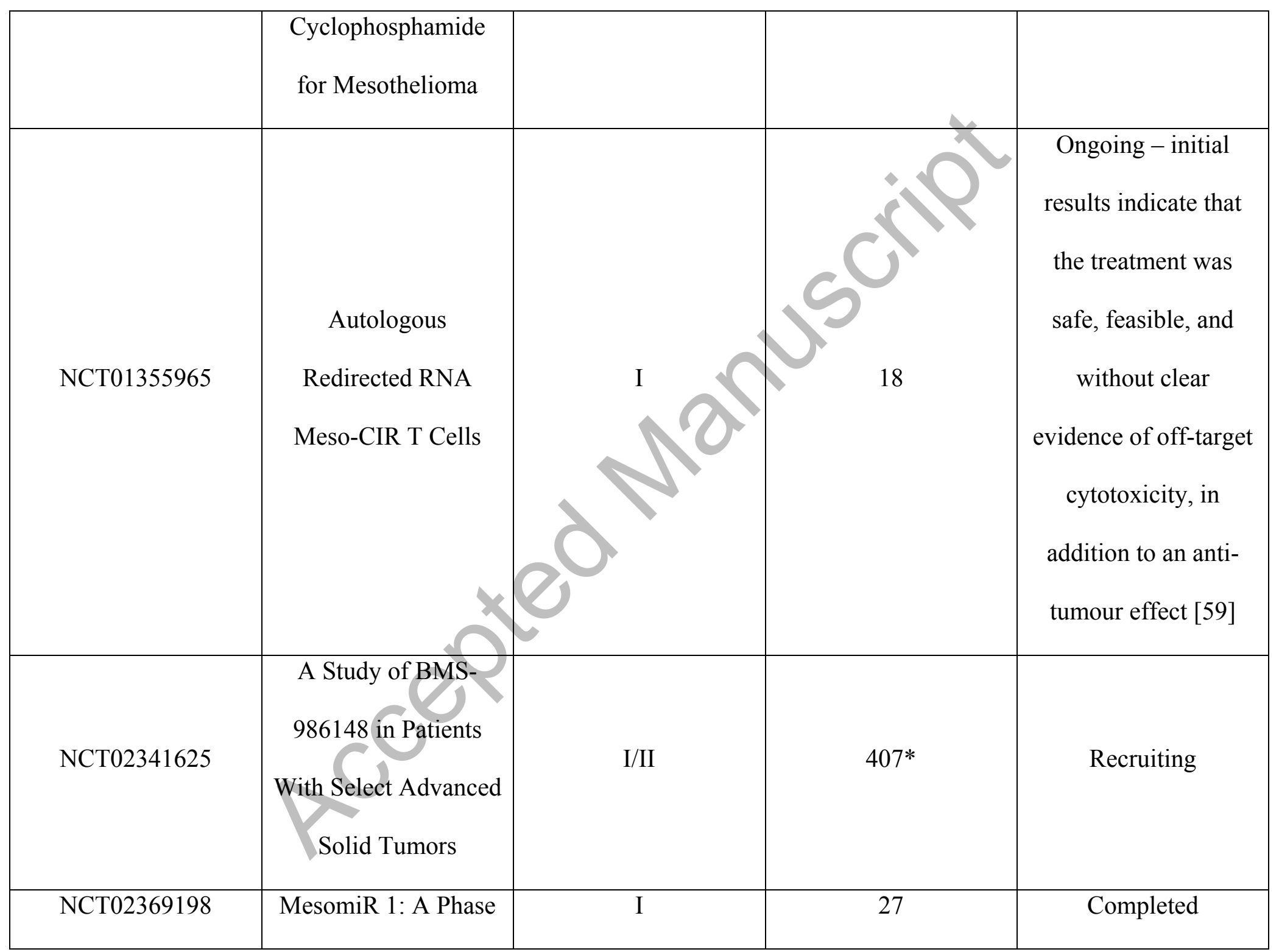




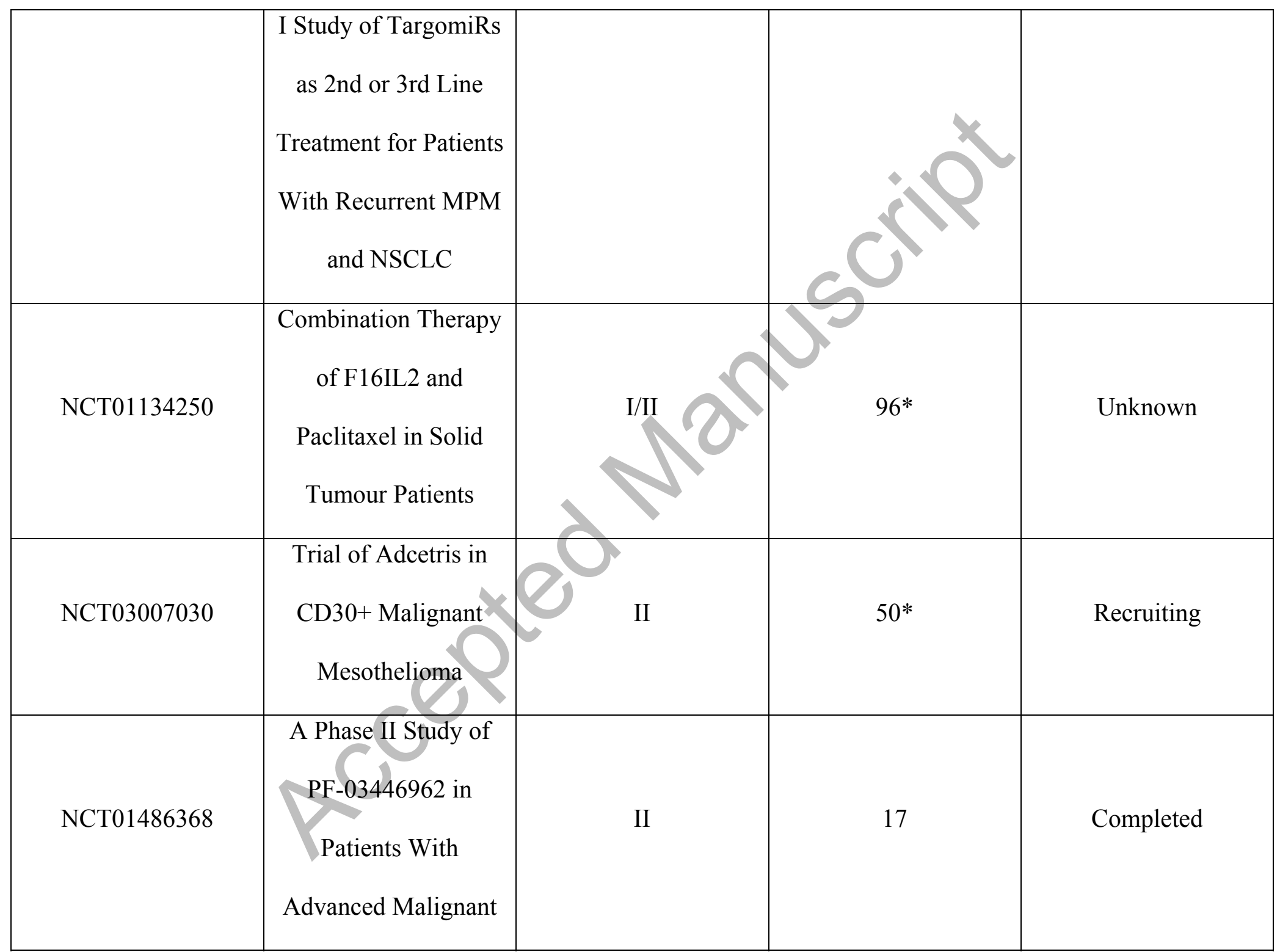




\begin{tabular}{|c|c|c|c|}
\hline & Pleural Mesothelioma & & \\
\hline NCT01439152 & $\begin{array}{c}\text { Phase I Study to } \\
\text { Determine the } \\
\text { Maximum Tolerable } \\
\text { Dose of BAY94-9343 } \\
\text { in Patients With } \\
\text { Advanced Solid }\end{array}$ & 147 & $\begin{array}{l}\text { Ongoing - results } \\
\text { presented at ASCO } \\
2016 \text { indicated } \\
\text { adverse events to } \\
\text { include reversible } \\
\text { keratopathy and } \\
\text { gastrointestinal } \\
\text { disorders though } \\
\text { serious drug-related } \\
\text { adverse events were } \\
\text { low and there were no } \\
\text { drug-related deaths. } \\
\text { Preliminary data } \\
\text { showed durable } \\
\text { partial responses in }\end{array}$ \\
\hline
\end{tabular}




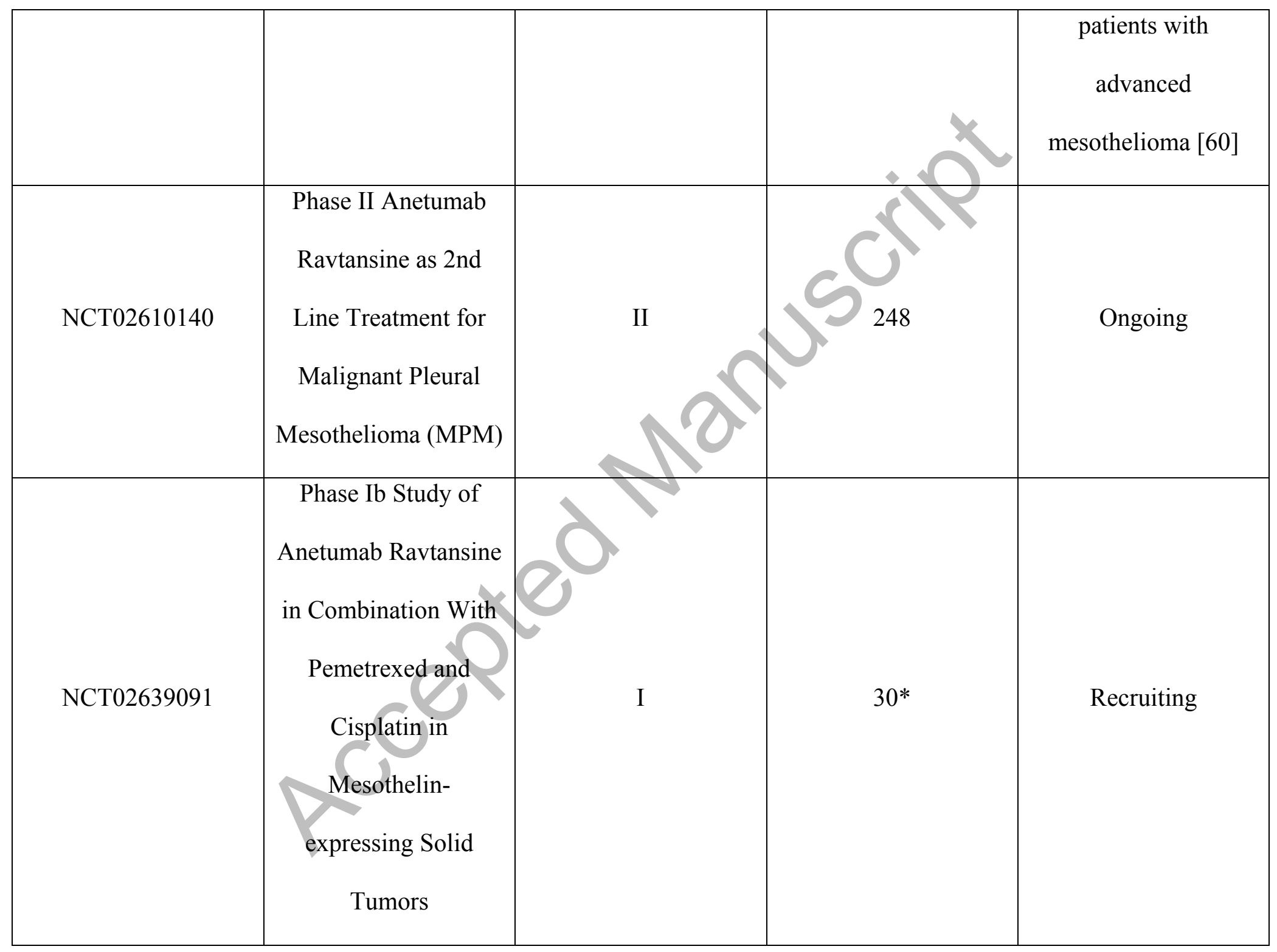




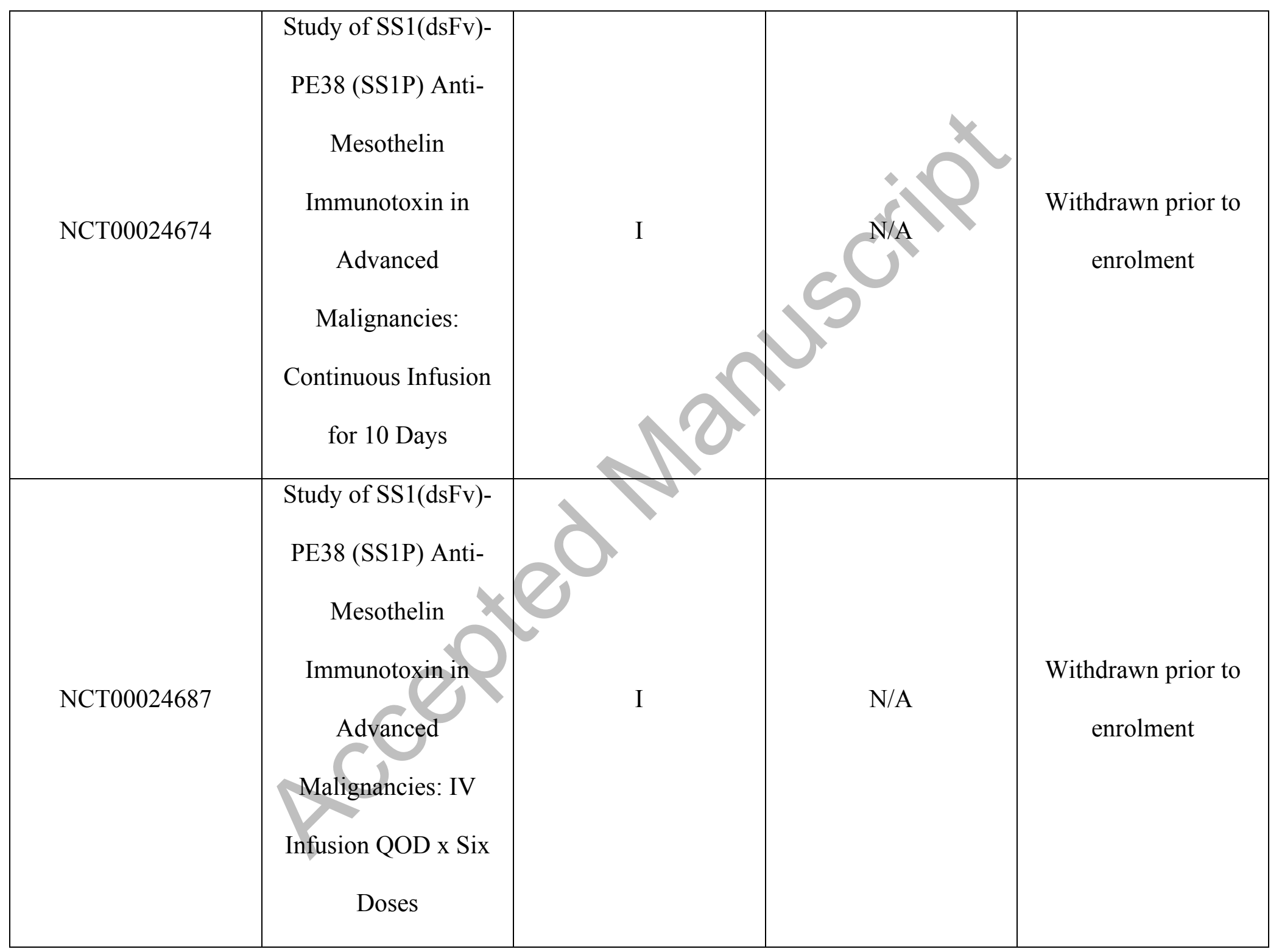




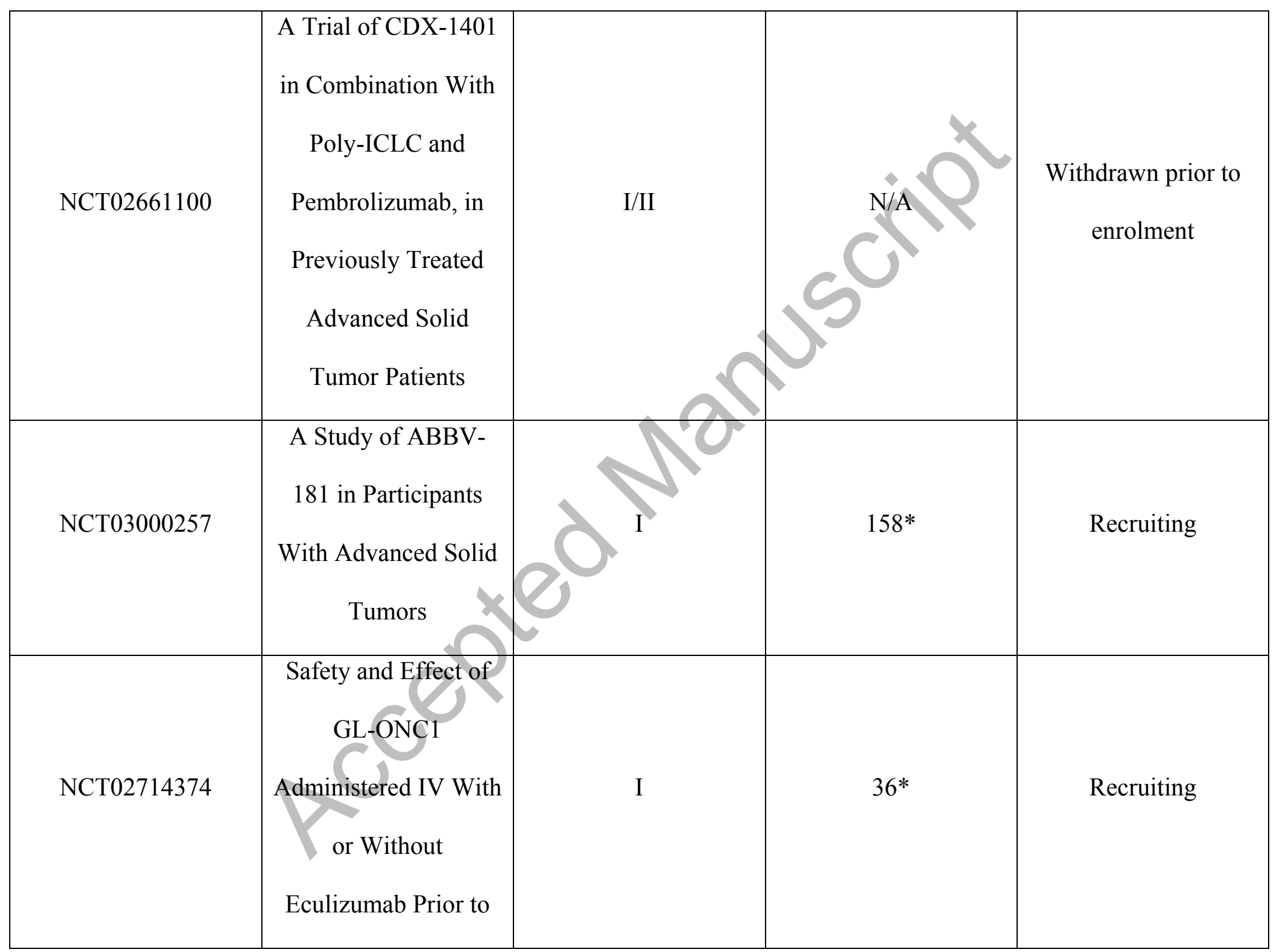




\begin{tabular}{|c|c|c|c|c|}
\hline & $\begin{array}{l}\text { Surgery to Patients } \\
\text { With Solid Organ } \\
\text { Cancers Undergoing } \\
\text { Surgery }\end{array}$ & & & \\
\hline NCT02628535 & $\begin{array}{c}\text { Safety Study of } \\
\text { MGD009 in B7-H3- } \\
\text { expressing Tumors }\end{array}$ & I & $4 *$ & Recruiting \\
\hline NCT02485119 & $\begin{array}{c}\text { Phase I Dose } \\
\text { Escalation Study of } \\
\text { BAY94-9343 Given } \\
\text { by Intravenous } \\
\text { Infusion Eyery } 3 \\
\text { Weeks in Japanese } \\
\text { Subjects With } \\
\text { Advanced } \\
\text { Malignancies }\end{array}$ & I & $15^{*}$ & Ongoing \\
\hline
\end{tabular}




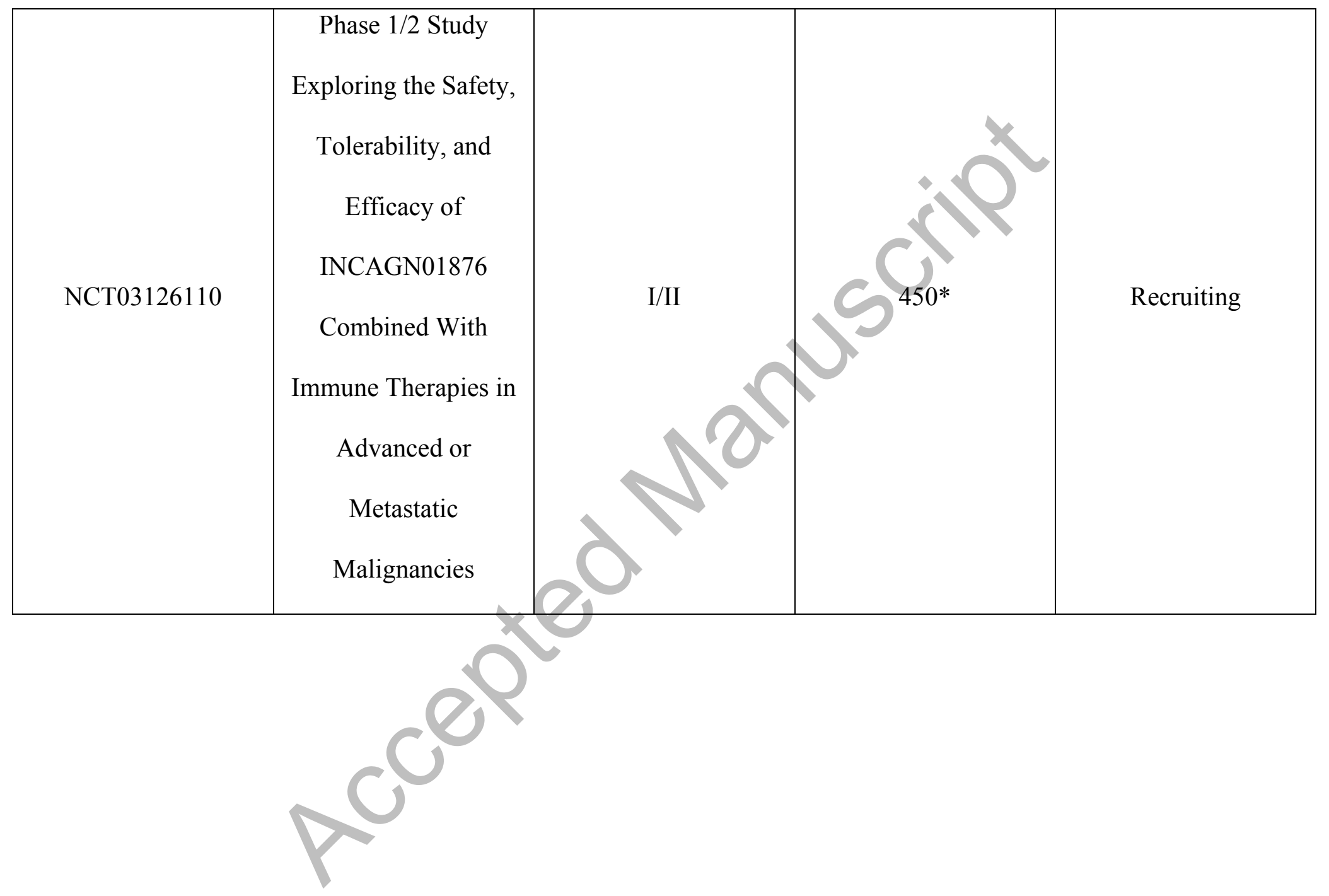


Table 4: Examples of clinical trials relating to the use of adoptive cell transfer in mesothelioma. An asterisk $(*)$ indicates that the number of patients is the projected accrual, not the number actually enrolled.

\begin{tabular}{|c|c|c|c|c|}
\hline $\begin{array}{c}\text { Clinical Trial } \\
\text { Identifier }\end{array}$ & Study Title & Phase & Number of Patients & $\begin{array}{c}\text { Status/Outcome of } \\
\text { Study }\end{array}$ \\
\hline NCT01722149 & $\begin{array}{l}\text { Re-directed T Cells } \\
\text { for the Treatment } \\
\text { (FAP)-Positive } \\
\text { Malignant Pleural } \\
\text { Mesothelioma }\end{array}$ & I & $6^{*}$ & Recruiting \\
\hline NCT02408016 & $\begin{array}{l}\text { Genetically Modified } \\
\text { T Cells in Treating } \\
\text { Patients With Stage } \\
\text { III-IV Non-small Cell } \\
\text { Lung Cancer or } \\
\text { Mesothelioma }\end{array}$ & $\mathrm{I} / \mathrm{II}$ & $20 *$ & Recruiting \\
\hline NCT01355965 & Autologous & I & 18 & Ongoing - initial \\
\hline
\end{tabular}




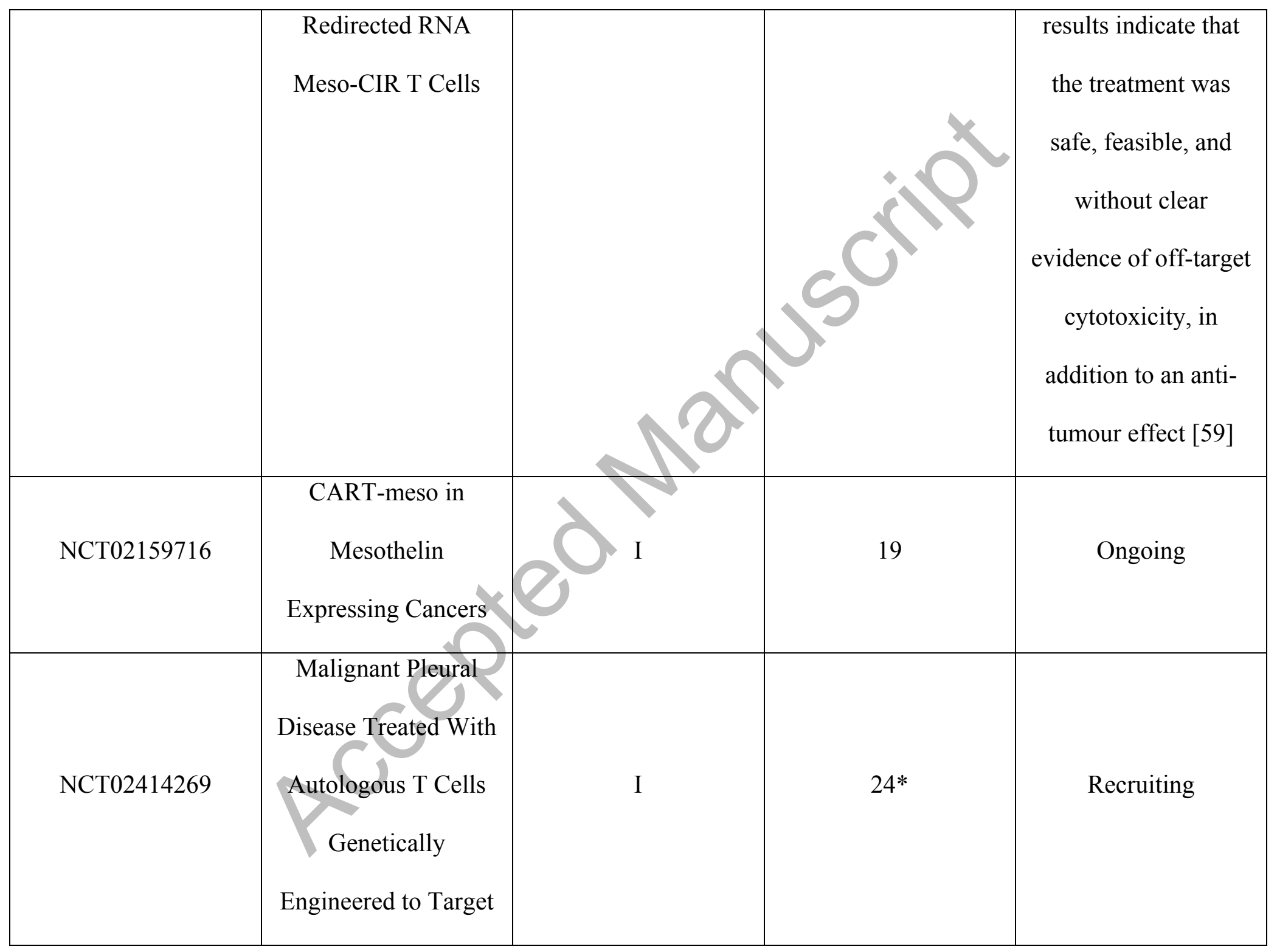




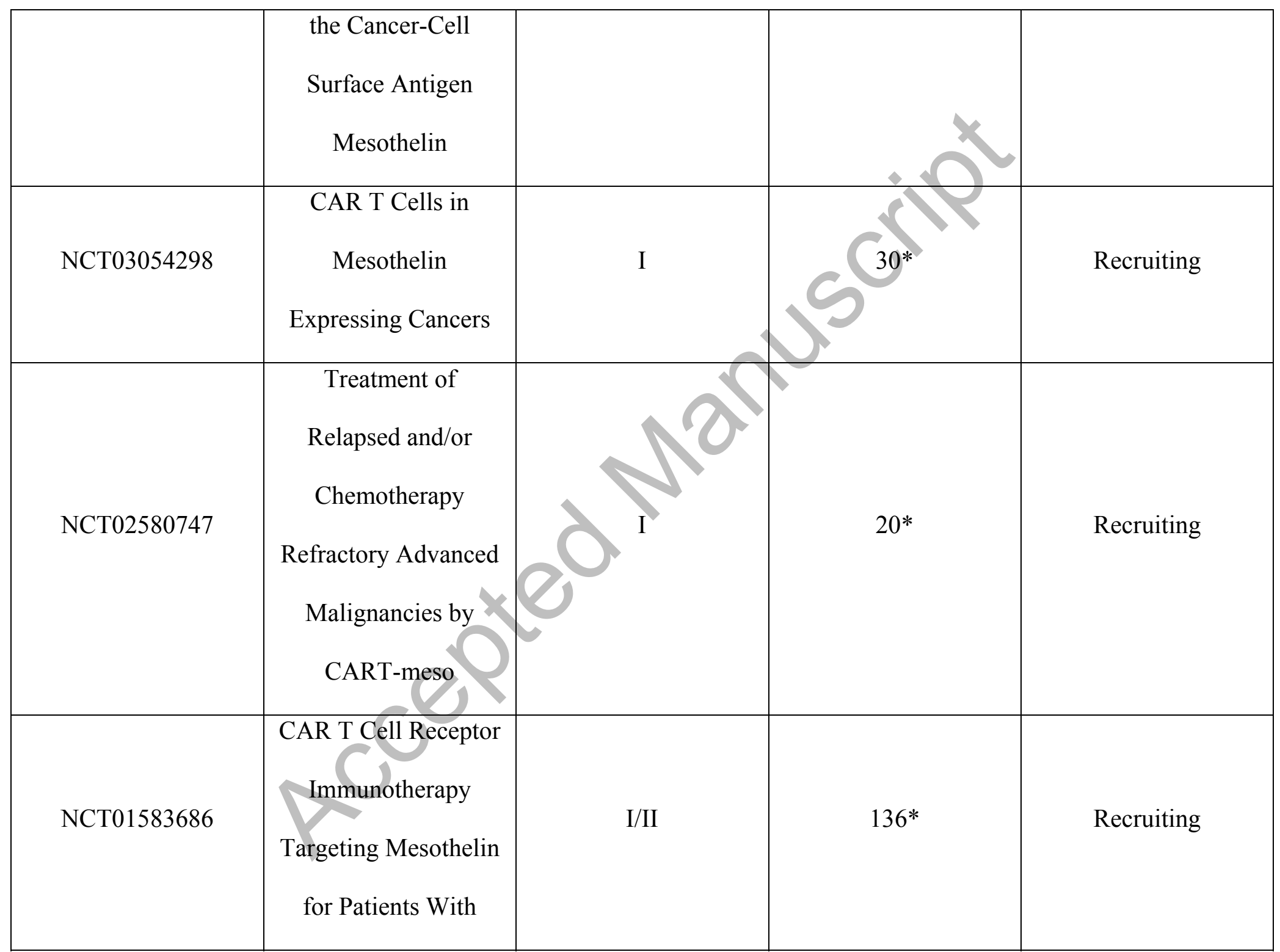




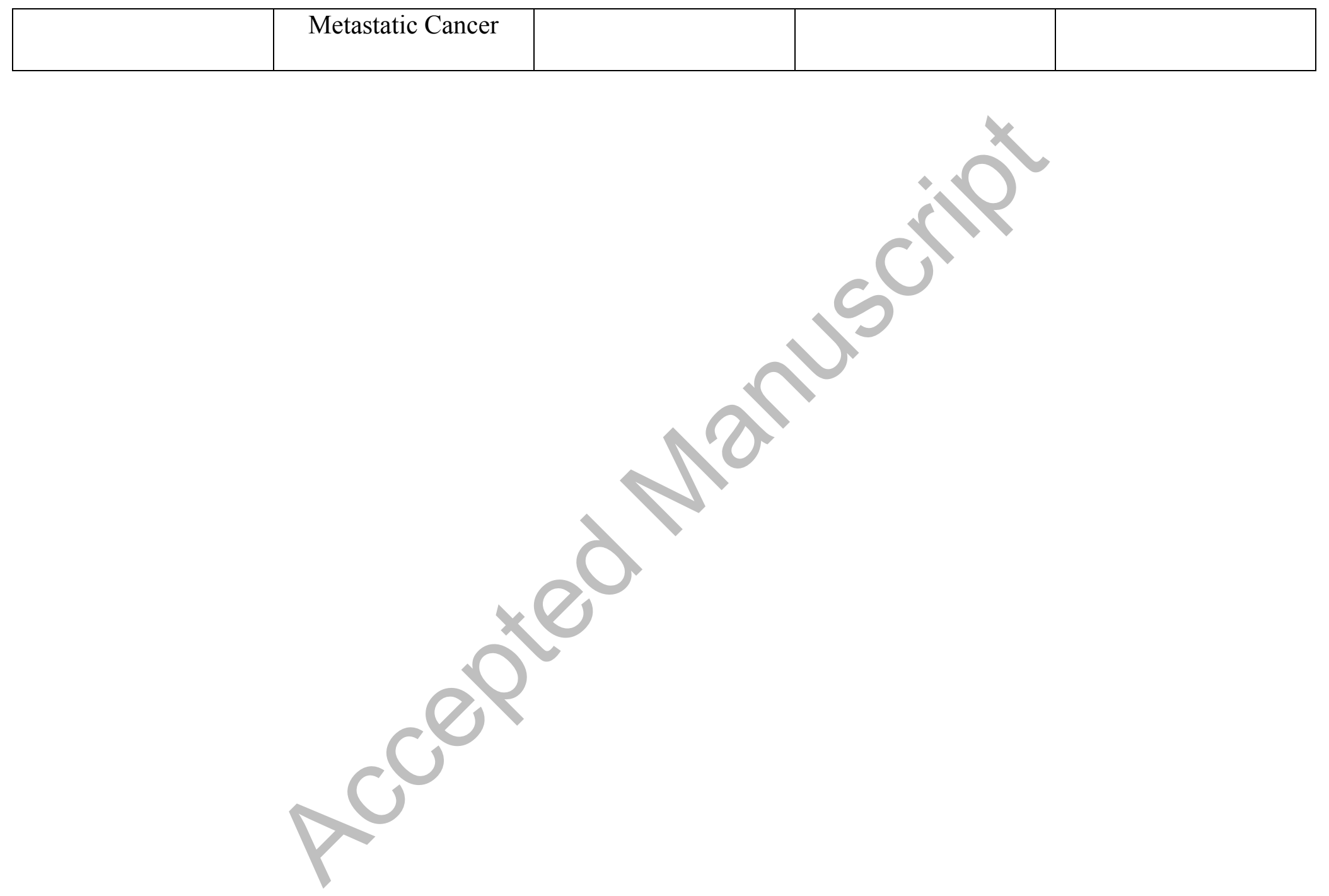




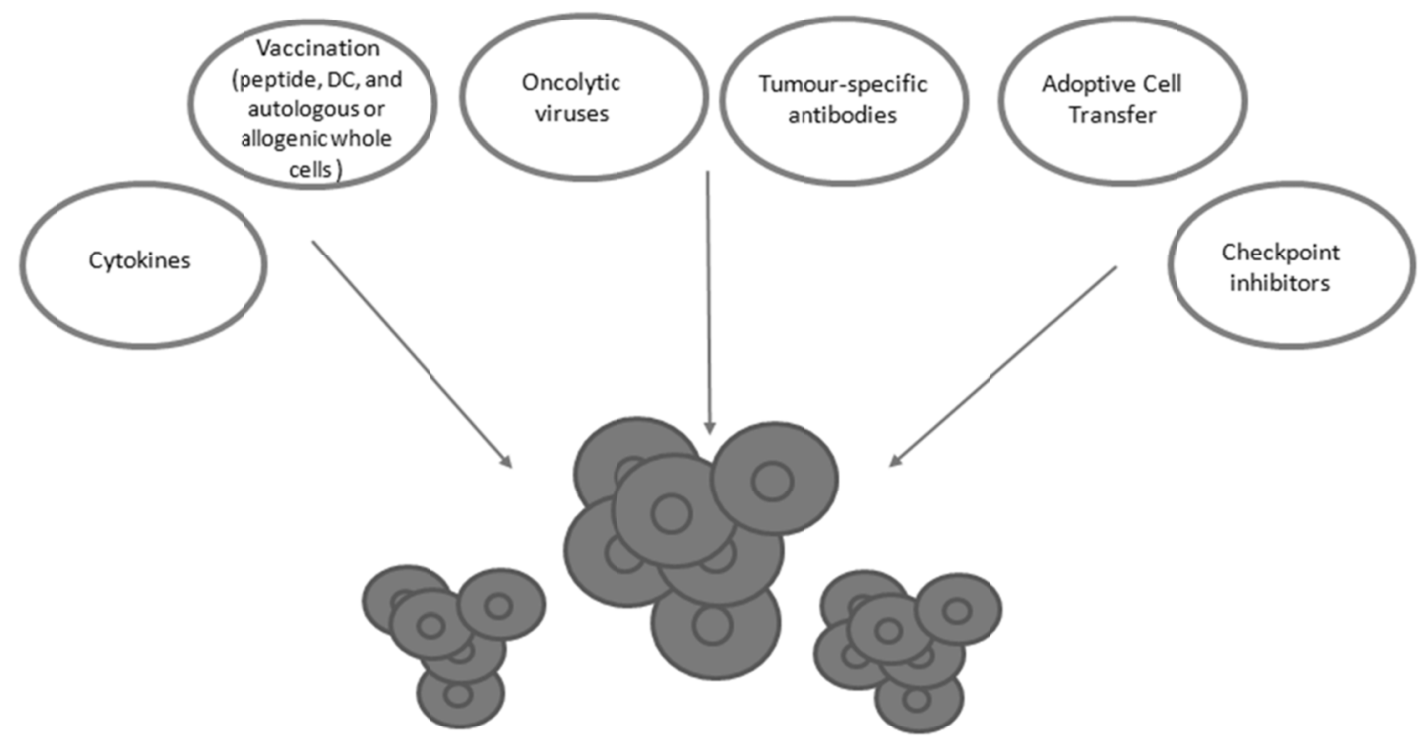

Figure 1: Overview of different immunotherăpeutic strategies. 
A
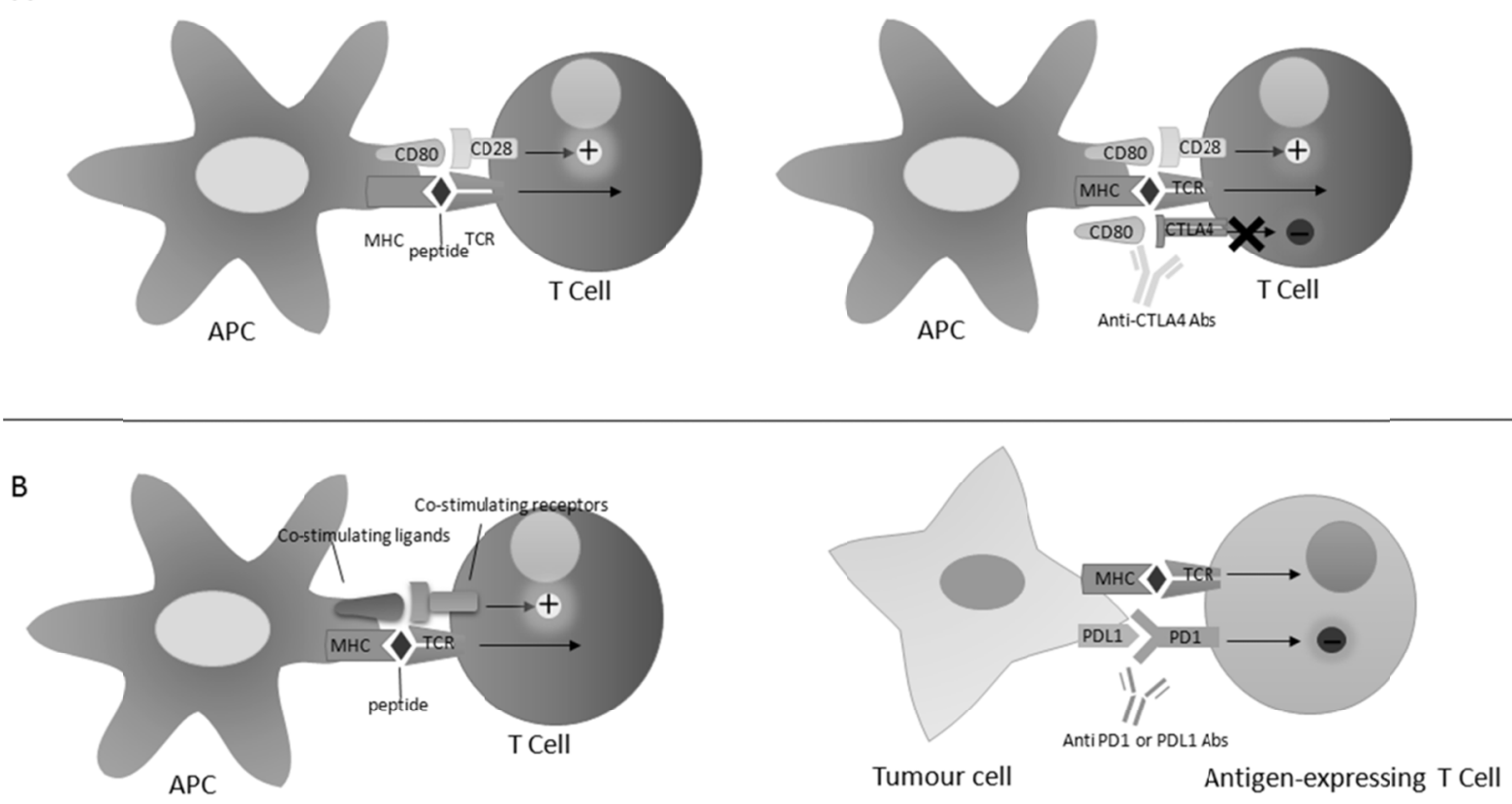

Figure 2: A) The activation of naivve $T$ cell requires signalling from TCR (signal 1) and CD28 (signal 2) which are expressed on their surface while CTLA4 is expressed intracellularly until TCR interacts with antigen from APC cells which promotes the migration of CTLA4 on the surface to attenuate the $T$ Cell response from TCR and CD28. Anti-CTLA4 antibodies block the interaction of CTLA4 with the ligand (CD80), allowing for enhanced antitumour response. B) PD1 is upregulated on $\mathrm{T}$ cell following the activation of $\mathrm{T}$ cell by TCR signalling and positive signals. PDI receptor interaction with the ligand PDL1 leads to attenuation of immune response. Anti-PD1/PDL1 antibodies block this signalling to enhance a antitumor immune response.

Abbreviations : CTLA4, cytotoxic T-lymphocyte antigen 4; PD1, programmed death 1;

PDL1, programmed death ligand 1; APC, antigen presenting cell; MHC, major

histocompatibility complex; TCR, T cell receptor. 